\title{
A Review on Electrochemical Sensors and Biosensors Used in Chlorogenic Acid Electroanalysis
}

\author{
Irina Georgiana Munteanu (D) and Constantin Apetrei * (D) \\ Department of Chemistry, Physics and Environment, Faculty of Sciences and Environment, "Dunărea de Jos" \\ University of Galaţi, 47 Domneasca Street, 800008 Galaţi, Romania; georgiana.munteanu@ugal.ro \\ * Correspondence: apetreic@ugal.ro; Tel.: +40-727-580-914
}

Citation: Munteanu, I.G.; Apetrei, C. A Review on Electrochemical Sensors and Biosensors Used in Chlorogenic Acid Electroanalysis. Int. J. Mol. Sci. 2021, 22, 13138. https://doi.org/ 10.3390/ijms222313138

Academic Editor: Emmanuel Stratakis

Received: 3 November 2021

Accepted: 2 December 2021

Published: 5 December 2021

Publisher's Note: MDPI stays neutral with regard to jurisdictional claims in published maps and institutional affiliations.

Copyright: (c) 2021 by the authors. Licensee MDPI, Basel, Switzerland. This article is an open access article distributed under the terms and conditions of the Creative Commons Attribution (CC BY) license (https:// creativecommons.org/licenses/by/ $4.0 /)$.

\begin{abstract}
Chlorogenic acid (5-O-caffeoylquinic acid) is a phenolic compound from the hydroxycinnamic acid family. Epidemiological, biological, and biochemical studies concur to support the beneficial role of chlorogenic acid in human health, along with other dietary phenolic compounds. Thus, chlorogenic acid has been reported to exert inhibitory effects on carcinogenesis in the large intestine, liver, and tongue, and a protective action on oxidative stress in vivo, together with antiinflammatory, antidiabetic and antihypertensive activities. It is also claimed to have antifungal, antibacterial and antiviral effects with relatively low toxicity and side effects, alongside properties that do not lead to antimicrobial resistance. Due to its importance, numerous methods for determining chlorogenic acid (CGA), as well as for its derivatives from coffee beans and other plants, were elaborated. The most frequently used methods are infrared spectroscopy, high performance liquid chromatography (HPLC), capillary electrophoresis, liquid chromatography-mass spectrometry and chemiluminescence. Although these methods proved to be efficient for quantifying CGA and its derived products, a number of deficiencies were identified: they are time consuming, laborious, and require expensive instruments. Therefore, electrochemical methods have been developed and used in the determination of CGA in different nutraceuticals or food products. The present review aims to present the main progresses and performance characteristics of electrochemical sensors and biosensors used to detect CGA, as it is reported in a high number of relevant scientific papers published mainly in the last decade.
\end{abstract}

Keywords: chlorogenic acid; electrochemical sensor; enzyme; biosensor; antioxidant activity

\section{Introduction}

Currently, the popularity of healthy foods has led to better studies on the impact of phytochemical compounds. These represent one of the richest reservoirs of organic compounds with various structures, called secondary metabolites, unique for each individual species [1].

Unfavorable conditions for plants, such as extreme temperature, drought, heavy metals, nutritious deficiencies and high salinity, generate high concentrations of reactive oxygen species (ROS), which can produce oxidative stress. To avoid this, cells have a complex oxidative system, which contains enzymatic and non-enzymatic elements. The molecules of the non-enzymatic system have different action mechanisms, such as inhibition of enzyme activity, chelation of the trace elements involved in producing free radicals, absorption and inactivation of reactive species, or increase of protection through other means of antioxidant defense [2].

From among the thousands of secondary compounds present in plants, phenolic compounds play a fundamental role against oxidative stress, representing one of the most frequently synthesized and studied classes [3]. They may be found in various parts of plants, such as roots, leaves, flower petals, as well as in fruit skins, seeds and pulp, which are consumed by people or used as part of nutraceutical formulas [4]. Phenolic compounds 
are considered genuine antioxidants, being associated with benefits in terms of decreasing the risks related to the onset of chronic diseases, as has been demonstrated by numerous reviews on their biological activity $[5,6]$.

Phenolic compounds are metabolites frequently present in various plant sources, and play a major role in human health due to their antioxidant activity and their antiinflammatory, antimicrobial and anticarcinogenic properties [7]. As antioxidants, these compounds can protect the cellular constituents against oxidative deterioration and, therefore, limit the risk of the onset of various degenerative diseases associated with oxidative stress [8]. They are capable of neutralizing free radicals by donating an electron or a hydrogen atom [9]. Moreover, phenolic compounds can increase the activity of endogen antioxidant enzymes such as glutathione peroxidase, superoxide dismutase and catalase, and inhibit the activity of enzymes such as xanthinoxidase.

In 2020, H. B. Rashmi et al. published a detailed paper describing the properties of phenolic compounds related to their bioavailability and benefits for human health, as well as aspects connected to their stability during processing and storage [10].

From a structural point of view, phenolic compounds contain one or more aromatic rings substituted with hydroxyl groups, covering a wide variety of chemical structures, from simple molecules to polymeric compounds [11]. Figure 1 shows the scheme of the main classes of phenolic compounds.

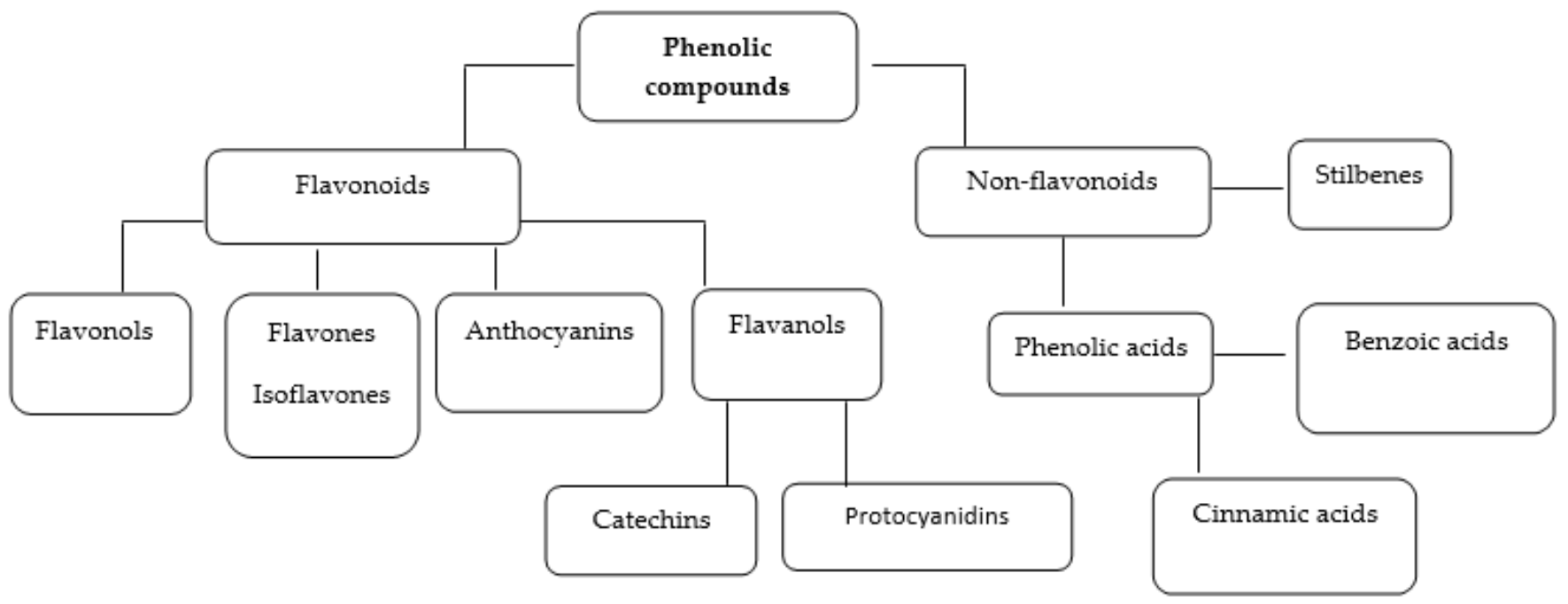

Figure 1. The main classes and subclasses of phenolic compounds.

Benzoic acids and cinnamic acids belong to the class of phenolic compounds. The chemical structures of phenolic acids are presented in Table 1.

Benzoic acids represent a class of phenolic compounds which contain seven carbon atoms (C1-C6) and which are present in foods, being frequent components of a complex structure, associated with hydrolysable tannins, sugars or lignin [12]. Derivatives of benzoic acid are produced through methoxylation or through the hydrolyzation of hydro benzoic acids. This category includes: benzoic acid, p-hydroxybenzoic acid, vanillic acid, gallic acid, syringic acid, veratric acid and salicylic acid [13].

Cinnamic acids are aromatic compounds with a side-chain of three carbon atoms (C3-C6), having ten carbon atoms in its structure. These participate in enzymatic oxidation reactions [14] and have, in turn, a series of compounds, including: cinnamic acid, ocoumaric acid, m-coumaric acid, p-coumaric acid, ferulic acid and caffeic acid. By cycling the lateral chain of the coumaric acid, the cinnamic acids can give other compounds, such as coumarins [15]. 
Table 1. Chemical structures of phenolic acids.

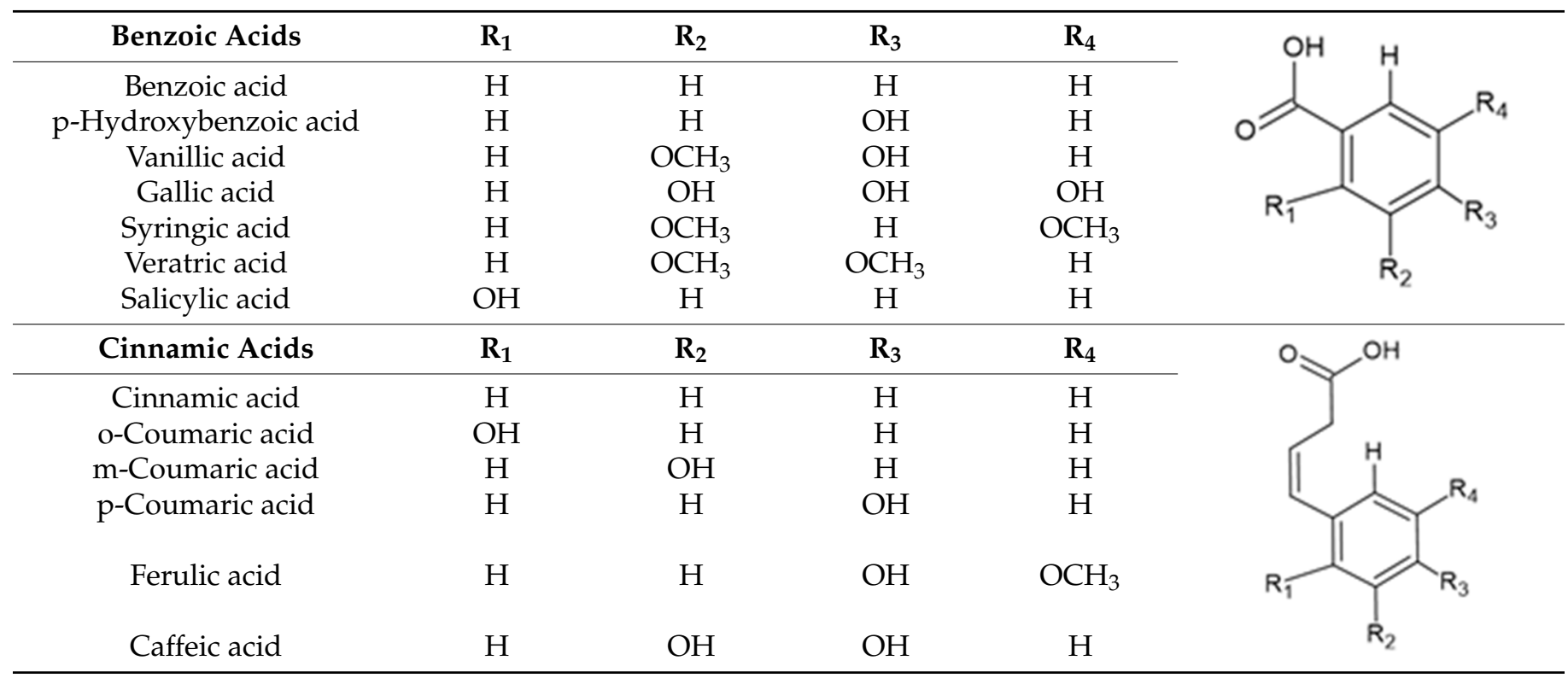

Many researchers have investigated this class of phenolic compounds present in a wide range of foods, from extraction and separation, to their identification and quantification. However, the study of compounds has encountered certain problems due to the high number of substances involved (thousands of compounds) and to their high polarity, compounds being very reactive and sensitive to enzyme action [16]. Among phenolic compounds, chlorogenic acid is of great interest because it has beneficial properties and the detection of this compound from natural samples is challenging.

\section{General Information Regarding Chlorogenic Acid}

Chlorogenic acids (CGAs) are natural compounds, predominant in superior plants. They represent a family of esters, formed between the quinic acid and certain trans-cinnamic acids. A series of conjugated structures—such as caffeoylquinic acid, di-caffeoylquinic acid, feruloylquinic acid and p-coumaroylquinic acid-exists, in several isomeric forms, in coffee beans [17].

CGA, (1S,3R,4R,5R)-3-\{[(2E)-3-(3,4-Dihydroxyphenyl)prop-2-enoyl]oxy\}-1,4,5-trihydroxycyclohexane-1-carboxylic acid, is the most abundant isomer found in nature and the most identified and quantified in natural samples.

The chemical structure of CGA is presented in Figure 2.<smiles>O=C(/C=C/C1=CC(O)C(O)C=C1)O[C@@H]1C[C@@](O)(C(=O)O)C[C@H](O)[C@H]1O</smiles>

Figure 2. Chemical structure of chlorogenic acid. 
CGA was studied on a wide scale due to the fact that it is one of the main phenolic compounds of the human diet, with multiple benefits for human health. The compound is found in foods and aromatic plants such as: apples [18], artichokes [19], carrots [20], coffee beans [21], potatoes [22], grapes [23], tobacco leaves [24], tea [23], wormwood [25] and honeysuckle [26].

In recent years, a series of benefits for human health has been associated with CGA consumption. From among these, the following are noteworthy:

- Modulates the glucose metabolism in humans; therefore, CGA has an antidiabetic effect [27] on type 2 sugar diabetes, improving the quality of insulin;

- $\quad$ Prevents the development of cataracts as a result of its antidiabetic effect; this aspect has been indicated by the findings of studies carried out on laboratory animals;

- $\quad$ Reduces the relative risk of cardiovascular diseases, improving human vasoreactivity; moreover, it has antihypertension properties [28];

- $\quad$ Reduces the risk of biliary calculi production.

In laboratory tests, it has been shown that CGA has antioxidant properties, preventing cell deterioration [29]. Nevertheless, scientific evidence of preventive effects against chronic diseases remains unsubstantial, since CGA decomposes very rapidly in the human organism.

Moreover, CGA has anti-inflammatory [29] and anti-neurodegenerative [30] properties, contributing to the decrease of Alzheimer's onset. In addition, most of the research carried out in relation to CGA's benefits for human health focused on metabolic syndrome disorders, with the metabolic syndrome defined as the sum of physiological, metabolic, biochemical and clinical interrelated factors, which increase the risk of cardiovascular disease, type 2 sugar diabetes and, implicitly, of mortality due to various causes [31].

A study achieved in 2011 evaluated the antibacterial activity and the action mechanism of CGA against bacteria. The data on the minimum inhibition concentration (MIC) values showed that CGA had efficiently inhibited the increase of all the bacterial pathogen agents tested, and the MIC values ranged from 20 to $80 \mu \mathrm{g} / \mathrm{mL}$. A study on the action of CGA against the pathogen agent indicated that this compound increased significantly the exterior and the permeability of the plasmatic membrane, the result being the loss of the barrier function. In short, CGA killed the strains of pathogen bacteria through causing irreversible modifications of the cellular membrane permeability [32].

\section{Pharmacokinetics of CGA}

In a different experimental model regarding humans and animals, CGA and its metabolites were noticeable in the blood circulation system [33]. The main metabolites of CGA were ferulic, isoferulic and caffeic acid, which has been examined in the systemic circulation after regular consumption of coffee or green coffee extract. One-third of ingested CGAs contained in beverages and foods are physiologically absorbed in the small intestine. This can be measured chromatographically in the forms of 5-CQA, 4-CQA and 3-CQA in plasma by high-performance liquid $[34,35]$. The remaining two-thirds reach the large intestine where phenolic acid is further metabolized by the gastrointestinal microflora and then absorbed. The small intestine is the site where cleavage of quinic acid from FQA (feruloyl quinic acid) and CQA and then the release of ferulic acid and CA biochemically occurs. Furthermore, the colon plays a significant role in the conversion of both caffeic and ferulic acid to dihydroferulic acid and a major role in its absorption (Figure 3) [36].

Given that CGA is a compound of great interest, with many health benefits, developing reliable, simple, rapid and sensitive methods for its quantification is of major importance. Until now, various methods used in determining CGA have been describedfrom classical analytical determining methods to electrochemical methods involving the use of electrochemical sensors and biosensors. 


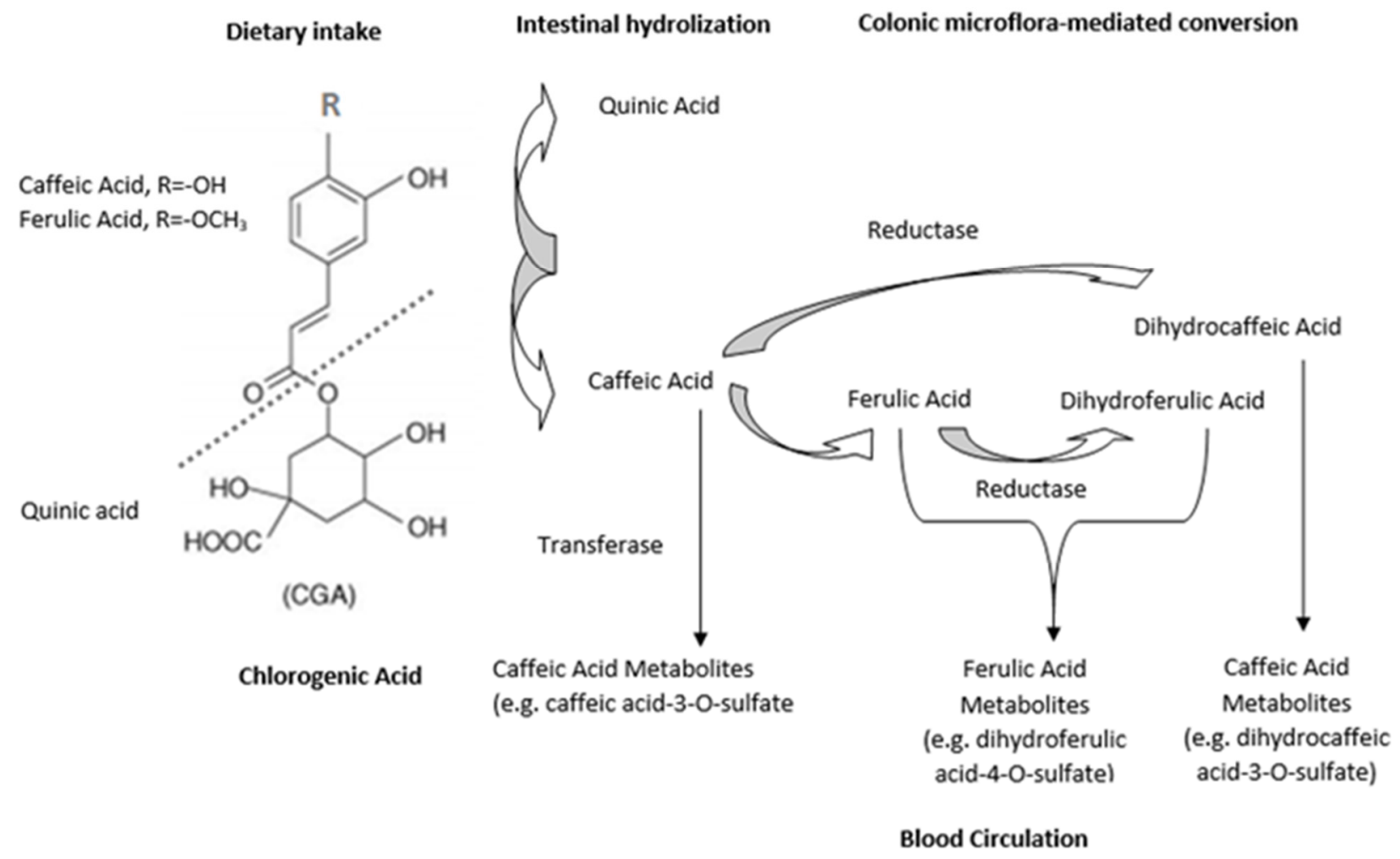

Figure 3. The major metabolic pathway of CGAs.

\section{Analytical Methods Used in Determining CGA}

\subsection{Instrumental Methods}

Numerous analytical instrumental methods for determining CGA have been developed so far. Worth mentioning are the following: high performance liquid chromatography (HPLC), infrared spectroscopy, capillary and chemiluminescent electrophoresis.

\subsubsection{HPLC}

HPLC is a separation method used in analytical chemistry to separate, identify and quantify chemical compounds. It is based on the different distribution of the components of a mixture between two phases: the stationary phase and the mobile phase [37].

Using this method, two collaborators, W. Liao and Y. Rui, determined CGA in the Lonicerae flos plant, the method's principle involving the separation of this compound. The detection wavelength was set to $327 \mathrm{~nm}$ so as to determine the CGA content. Linearity was obtained in the range $8.8-89 \mu \mathrm{g} / \mathrm{mL}(\mathrm{r}=0.9999)$. Its average analytical recovery was $98.1 \%$, and the relative standard deviation (RSD) was $1.85 \%(n=51)$. The precision of the method was $0.82 \%(n=5)[38]$.

Another study was carried out in 2012 and involved establishing a content determination method for CGA and 2-O-rhamnoside vitexin from Crataegi fructus extract through HPLC. Good values of linearity were obtained for both compounds, in the 1.34-164.80 and $1.18-148.7 \mathrm{mg} \cdot \mathrm{L}^{-1}$ ranges. The analytical recoveries were $100.4 \%$ and $98.8 \%$, while RSD were $1.5 \%$ and $1.3 \%$, respectively [39].

L. Borisova-Jan et al. developed, in 2017, a HPLC based method of quantifying the derivatives of the caffeoylquinic acid in Hieracium pilosella $\mathrm{L}$. The content of derivatives in the caffeoylquinic acid was determined and expressed as CGA. Validation showed that the chromatographic method has good selectivity, without interference peaks. Sensitivity, precision and repeatability proved adequate. The linearity of the sensor's response to the compounds analyzed was between 1.5 and $150 \mu \mathrm{g} / \mathrm{mL}$, corresponding to 0.03 , up to $3 \%$ $(\mathrm{g} / \mathrm{w})[40]$. 
Furthermore, in 2018, an analytical method based on separation with the aid of HPLCwith diode group detection for synchronized determination of CGA and five flavonoids (rutin, isoquercetin, quercetin, quercitrin, luteolin) in mulberry leaves (Morus sp.)-was developed and validated. In optimum working conditions, the extraction of CGA and of flavonoid compounds was achieved, with average analytical recovery values between $97.78 \%$ and $103.24 \%$. The developed method was validated in relation to linearity, analytical recovery, precision and stability [41].

Another chromatographic method used for determining the CGA concentration in green coffee was liquid chromatography in reverse phase. It was described by a group of researchers in 2020. The identification was carried out through comparing the retention time of the pure analytical standard with the retention time of the CGA in the analyzed samples. An excellent linearity was obtained in the $12.33-143.50 \mu \mathrm{g} / \mathrm{mL}$ range. The value of the detection limit was $0.29 \mathrm{pg}$, and that of the quantification limit was $0.96 \mathrm{pg}$. The obtained results demonstrated that the used method was characterized by a wide linearity range, and that it was precise, with analytical recoveries between 97.87 and $106.67 \%$ [42].

\subsubsection{Near Infrared Spectroscopy (NIRS)}

NIRS was proposed, in 2015, as a rapid and non-destructive method for the evaluating content in relation of three compounds (caffeic acid, catechin and CGA) and three methylxanthines (caffeine, theophylline and theobromine) in samples of ground coffee from various producers. Good linearity ranges were obtained, with determination coefficients of $0.95,0.92,0.88,0.71$ and 0.84 for caffeine, caffeic acid, catechin, chlorogenic acid and theophylline [43].

The feasibility of the NIR method for determining CGA, luteolin and 3,5-O-dicaffeoylquinic acid in species of Chrysanthemum was analyzed in a study published in 2019 . The values of the prediction correlation coefficient $\left(\mathrm{r}_{\mathrm{p}}{ }^{2}\right)$ were: $0.924,0.927,0.933$ for CGA, luteolin and 3,5-O-di-caffeoylquinic acid. The results indicated that NIR spectroscopy, combined with multivarious calibration methods, could be considered a useful tool in the rapid determination of biological compounds active in Chrysanthemum species [44].

A recent study (2021) was based on Fourier transform near infrared spectroscopy (FT-NIR). This method is used to determine the compounds in the samples and to classify them. This study developed a rapid, simultaneous, non-destructive method of analysis for eight compounds in the Flos Mume plant. The results indicated that only the neochlorogenic acid, CGA, rutin, hyperoside (quercetin-3-O-galactoside) and isoquercetin had concentration values which could be determined, the CGA content being the largest. The other components were excluded due to low concentrations. Through this study, a distinction among the various types of Flos Mume could be made, based on the CGA content, which shows that CGA has the potential to become a key indicator for use in quality evaluation [45].

\subsubsection{Capillary Electrophoresis}

The technique of local capillary electrophoresis, combined with the assisted extraction of microwaves, was developed for the very first time in 2010 by Z. Li et al. to rapidly quantify CGA in tobacco residues. Being a new method, this procedure was optimized, validated and compared to conventional methods, namely extraction by ultrasound and extraction through reflux. The obtained results demonstrated that the technique of local capillary electrophoresis, combined with the assisted extraction of microwaves, has good linearity $\left(\mathrm{R}^{2}\right.$ is $\left.0.991,0.003-0.5 \mathrm{mg} / \mathrm{mL}\right)$, detection limit $(0.003 \mathrm{mg} / \mathrm{mL})$ and quantification limit $(0.01 \mathrm{mg} / \mathrm{mL})$, as well as adequate precision, with an RSD value of $4.28 \%$ [46].

Another study, carried out in 2012, described a new method of infrared assisted extraction, doubled by electrophoresis, used to determine CGA in a traditional Chinese medicine, namely honeysuckle. The effects of $\mathrm{pH}$ and the concentration of the buffer solution, the tension applied for separation, the injection time, the IR irradiation time and the concentration of the standard sample in the extraction solution were all analyzed. Good 
linearity $\left(r^{2}>0.9996\right)$ in the studied concentration range was observed, and the stability of the solutions was found to be high. The CGA analytical recoveries were $95.53 \%$ up to $106.62 \%$, and the relative standard deviation was under $4.1 \%$ [47].

A rapid and safe method based on capillary electrophoresis to simultaneously determine twenty polyphenolic compounds in less than 27 min was described, in 2015, by F. Gatea et al. It was assumed that these compounds are found in propolis and plant extracts, CGA being one of them. The linearity ranges used to quantify the compounds was satisfactory, with correlation coefficients between 0.997 and 0.999 for all the twenty compounds analyzed. The method showed good performance characteristics, namely detection and quantification limits from 0.02 to 1.75 and from 0.07 to $5.77 \mu \mathrm{g} \cdot \mathrm{mL}^{-1}$, respectively. The values of the relative standard deviation for repeatability did not go above $4.86 \%$ for intra-daily tests and $5.07 \%$ for inter-daily tests. The results of the analytical recovery tests were between $87.4 \%$ and $114.2 \%$ for the Origanum sample, and between $85.0 \%$ and $111.0 \%$ for the propolis sample [48].

\subsubsection{Chemiluminescence}

In 2007, Wang et al. described a method for detecting CGA based on the chemiluminescent reaction of potassium permanganate with CGA in the presence of formaldehyde as potentiator. This indicated a difference in the intensity of potassium permanganate chemiluminescence and formaldehyde in the presence of CGA, as compared to that in the absence of CGA, for a concentration range from $5.0 \times 10^{-8}$ to $5.0 \times 10^{-5} \mathrm{~g} / \mathrm{mL}$. The detection limit obtained was $5.7 \times 10^{-9} \mathrm{~g} / \mathrm{mL}$ when the collection rate was 150 injections per hour. The method was applied successfully to determine CGA in fruit, with analytical recoveries of $100 \pm 6 \%$ [49].

In 2020, a rapid and simple method was developed to determine various phenolic acids (ferulic acid, CGA and salicylic acid) in plants through capillary electrophoresis with chemiluminescent detection. The simple chemiluminescent detection was carried out in a temperature-controlled laboratory constructed interface, through using potassium permanganate as chemiluminescent reactive. The detection limits for ferulic acid, CGA and salicylic acid were 35,58 and $37 \mu \mathrm{g} / \mathrm{mL}$, and the quantification limits were 117 , 193 and $123 \mu \mathrm{g} / \mathrm{mL}$. The proposed method was applied successfully in the quantitative determination of the phenolic acids in Lonicera japonicaflos and Rhizoma Chuanxiong [50].

Among these reported methods, near infrared spectroscopy (NIR) needs expensive equipment and calibrations, which involves supplementary costs in carrying out the determinations. The analyses through capillary electrophoresis have the disadvantage of not being very sensitive. The chromatographic methods need large quantities of organic solvents, expensive and laborious equipment [51]. By comparison, the UV-Vis method has the advantage of being simple, cheap and rapid in determining CGA in coffee beans. Nevertheless, a direct spectral determination of coffee beans is difficult to carry out due to the spectral overlap with caffeine [52].

Although these instrumental methods have proven to be efficient in quantifying CGA and its derivatives, a series of disadvantages has also been noted: they are time consuming and laborious, necessitating expensive equipment to carry out analyses [53].

\subsection{Electrochemical Methods}

In recent years, electrochemical methods have been investigated on a wide scale in view of determining phenolic compounds, the main reasons being their simplicity, high sensitivity, rapid response and reduced cost [54]. In addition to their use in the fundamental processes of oxidation and reduction to discover reaction mechanisms, these techniques are also used in studying the kinetics and thermodynamics of ion and electron transfer processes [55].

Electrochemical methods represent, most likely, one of the most adequate options in connection with phenolic compounds. The largest part of the biological activity of these compounds is due to their capacity to donate electrons to a wide range of receiving species. 
The redox potential of natural phenolic compounds covers a significant variety, which represents the first source of selection allowing the selective analysis of various electroactive compounds through various voltammetric techniques such as cyclic voltammetry (CV), differential pulse voltammetry (DPV) or square wave voltammetry (SWV) [56].

Electroanalytical methods were developed in view of determining CGA, even using metallic electrodes or carbon-based electrodes, without attempts at increasing selectivity through specific detection elements, but with the aim of improving sensitivity by coating with nanostructured materials, particularly graphene, carbon nanotubes or conducting polymers [57].

The electrochemical electrooxidation mechanism of CGA involves, in a first stage, the pre-dissociation of a proton with the formation of a monoanionic species. This, in turn, is oxidated to generate a radical. The radical formed is prone to a new rapid electronic transfer with the formation of a carbocation which, through dehydration, forms the adequate quinone. During reverse scanning, the quinone formed is reduced to CGA. This oxidation mechanism is presented in Figure 4 [58].

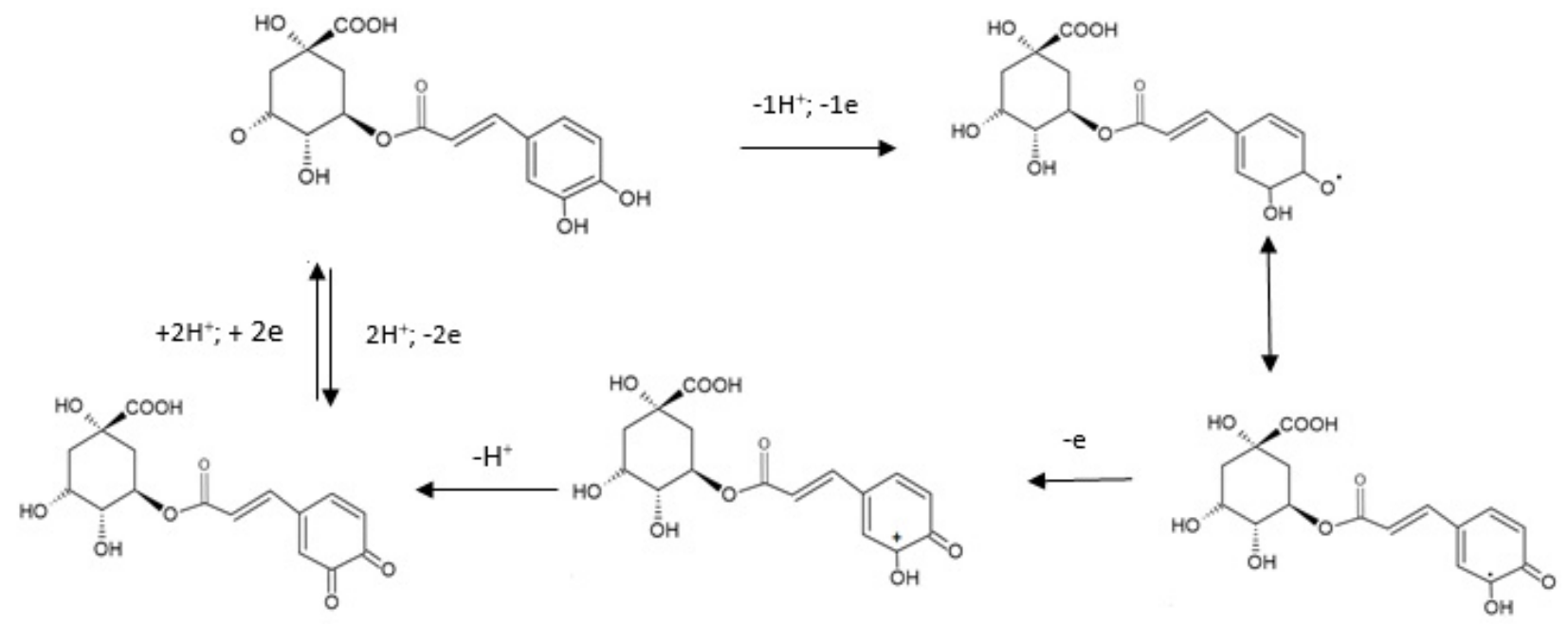

Figure 4. Electrochemical oxidation mechanism of CGA [58].

\subsubsection{Electrochemical Sensors Used in Determining CGA}

Through the years, several studies on establishing CGA with the aid of various electrochemical sensors based on modified electrolytes have been carried out.

A study carried out in 2011 focused on the construction of a molecularly imprinted electrochemical sensor for the selective detection of CGA through adding a molecularly imprinted siloxane film prepared through the sol-gel process onto the surface of the gold electrode. The surface of the molecularly imprinted siloxane film was electrochemically characterized using differential pulse voltammetry (DPV). The sensor obtained was tested both in a solution containing CGA and in solutions of other similar molecules, with an excellent selectivity towards CGA. The current of the anodic spot was linear in the $5.0 \times 10^{-7}-1.2 \times 10^{-5} \mathrm{~mol} / \mathrm{L}$ range. The detection limit was also calculated, with a value of $1.48 \times 10^{-7} \mathrm{~mol} / \mathrm{L}$ being obtained. To evaluate how applicable the sensor is, it was used to determine the CGA concentration in coffee and tea samples, with analytical recovery values between $94.3 \%$ and $107.9 \%$ being obtained, which suggests that the method has good precision and high potential in analyzing real samples [59].

In another study, carried out in 2016 by Ma. Xiaoyan et al., CGA was determined using a screen-printed carbon electrode with multi-walled carbon nanotubes (MWCNTs/SPE). Two detection techniques were used, namely: cyclic voltammetry (CV) and DPV. The influence of four supporting electrolytes on the sensor response was evaluated, as shown in Figure 5. A pair of redox peaks was highlighted in the case of all the support electrolytes 
used, but the highest peak was obtained for the $0.1 \mathrm{~mol} / \mathrm{L}$ acetic acid-sodium acetate buffer solution.

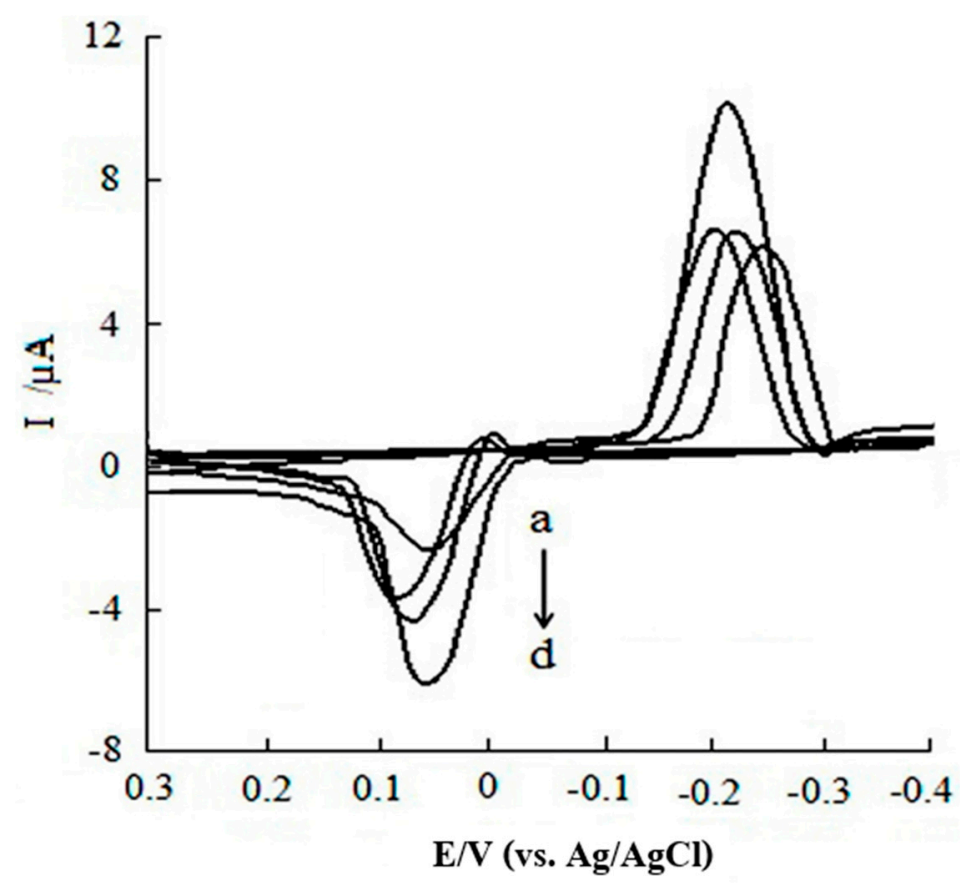

Figure 5. Influence of different supporting electrolytes on peak current: (a) $0.10 \mathrm{~mol} / \mathrm{L}$ potassium hydrogen phosphate-potassium dihydrogen phosphate buffer; (b) $0.10 \mathrm{~mol} / \mathrm{L}$ phosphate buffer solutions; (c) $0.10 \mathrm{~mol} / \mathrm{L}$ citric acid buffer; (d) $0.10 \mathrm{~mol} / \mathrm{L}$ acetic acid-sodium acetate buffer [52].

In optimum conditions, the method indicated linear ranges from 0.17 to $15.8 \mu \mathrm{g} / \mathrm{mL}$, a limit of detection of $0.12 \mu \mathrm{g} / \mathrm{mL}$ being obtained. The sensor was later used in the quantitative determination of CGA in coffee beans and green tea, a relative standard deviation (RSD) between $1.33 \%$ and $4.77 \%$ and analytical recoveries of $94.74-106.65 \%$ being obtained. The results achieved were compared to those of the HPLC method, a good correlation being noted [52].

Another study on the determination of CGA was based on the synthesis of a new compound, namely a $\mathrm{Fe}_{3} \mathrm{O}_{4}$ superparamagnetic nucleus encapsulated in an organic metal framework shell, $\mathrm{Fe}_{3} \mathrm{O}_{4} @ \mathrm{MIL} 100(\mathrm{Fe})$, through the layer-to-layer method. The thickness of the shell could be controlled through auto-assembly cycles between $\mathrm{FeCl}_{3} \cdot 6 \mathrm{H}_{2} \mathrm{O}$ and 1,3,5-benzenetricarboxylic acid. The characterization of the composite materials was performed through X-ray diffraction, transmission electronic microscopy (TEM), Fourier transform infrared spectroscopy and $\mathrm{N}_{2}$ adsorption/desorption isotherms. This material was used to obtain a new sensor to determine CGA. In optimum conditions, the electrochemical sensor was shown to quantitatively detect CGA in the $0.1-10.0 \mu \mathrm{mol} \cdot \mathrm{L}^{-1}$ and $10.0-460 \mu \mathrm{mol} \cdot \mathrm{L}^{-1}$ range. The detection limit was $0.05 \mu \mathrm{mol} \cdot \mathrm{L}^{-1}$. Another aspect studied was the repeatability of the sensor through seven successive determinations of $20 \mu \mathrm{mol} \cdot \mathrm{L}^{-1}$ CGA in PBS, with a relative standard deviation (RSD) of $4.2 \%$. The stability of the sensor was evaluated through carrying out 30 cycles, which indicated that the catalytic properties of the modified electrode were preserved, without a significant decrease of the current intensity. Finally, in view of determining the practical applicability of the new sensor, a test on the CGA content of the real samples was carried out through the method of addition, using DPV. The values of the analytical recoveries varied from $96.0 \%$ to $103.8 \%$, which shows that the new sensor has good precision and can be successfully used in analyzing real samples [60].

Another study carried out in 2016 was aimed to prepare a sensor based on metalorganic/titanium dioxide $\left(\mathrm{UiO}-66-\mathrm{NH}_{2} / \mathrm{TiO}_{2}\right)$ nanocomposite structures so as to determine CGA. The nanocomposite was prepared through a simple hydrothermal reaction, the 
electrocatalytic activity of the compound for CGA oxidation being due to the synergic effect of $\mathrm{UiO}-66-\mathrm{NH}_{2}$ and $\mathrm{TiO}_{2}$.

The electrochemical effect of CGA was studied at $\mathrm{pH}$ 6.0, using a phosphate buffer solution, through CV. In a PBS solution, the appearance of redox peaks cannot be noticed, which indicates the fact that the $\mathrm{UiO}-66-\mathrm{NH}_{2} / \mathrm{TiO}_{2}$ nanocomposite is not electroactive in the potential range selected. On adding CGA to PBS, a pair of redox peaks appears, which are attributed to the electrochemical behavior of CGA (Figure 6).

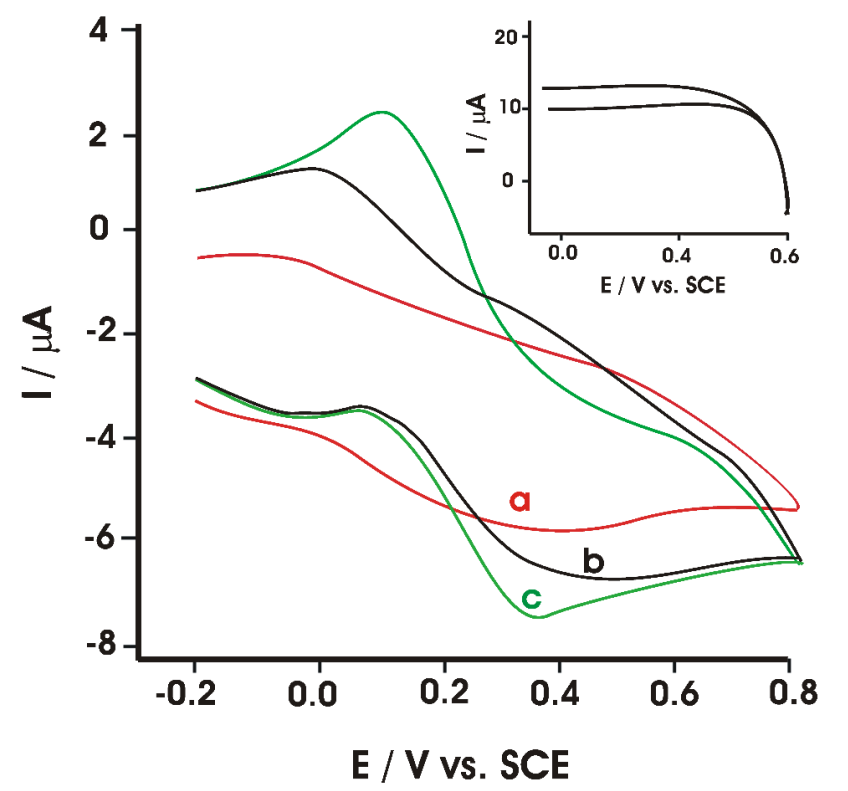

Figure 6. Cyclic voltammograms of chlorogenic acid at the bare GCE (a), UiO-66- $\mathrm{NH}_{2} / \mathrm{GCE}$ (b), and UiO-66- $\mathrm{NH}_{2} / \mathrm{TiO}_{2} / \mathrm{GCE}$ (c) in $0.1 \mathrm{~mol} \mathrm{~L}^{-1} \mathrm{pH}$ 6.0 PBS in the presence of chlorogenic acid. Scan rates: $100 \mathrm{mV} \cdot \mathrm{s}^{-1}$. Inset: Cyclic voltammograms of the $\mathrm{UiO}-66-\mathrm{NH}_{2} / \mathrm{TiO}_{2} / \mathrm{GCE}$ in $0.1 \mathrm{~mol} \mathrm{~L}^{-1} \mathrm{PBS}$ ( $\mathrm{pH}$ 6.0) in the absence of chlorogenic acid. Adapted from [61].

Cyclic voltammograms of the sensor immersed in $10.0 \mu \mathrm{mol} \cdot \mathrm{L}^{-1}$ CGA solution, at various scan rates, were also achieved. It was noticed that the current intensity is directly proportional with the square root of the scan rate, which suggests that the CGA redox process is influenced by the diffusion of the electroactive species on the electrode surface.

The variation of current intensity based on CGA concentration was studied next on the UiO-66- $\mathrm{NH}_{2} / \mathrm{TiO}_{2}$ surface, using DPV, as shown in Figure 7. From the results obtained, LOD was calculated, its value being $7 \mathrm{nmol} \cdot \mathrm{L}^{-1}$. The relative standard deviation of $3.67 \%$ for 9 measurements of $1.0 \mu \mathrm{mol} \cdot \mathrm{L}^{-1}$ CGA indicates the good repeatability of the analyzed sensor.

Finally, to confirm the performance of the proposed method in real samples, applicability was tested in coffee and tea samples. Good recoveries were obtained for all the samples, in the $96.0-102.0 \%$ range, suggesting that the proposed method is efficient and has high precision [61].

In 2007, N. Mohammadi et al. carried out a study which consisted in obtaining a modified carbon paste electrode, based on defective mesoporous carbon (DMC) and an ionic liquid (1-butyl-3-methylimidazolium-hexafluorophosphate-BMIM.PF 6 ) at room temperature, used in the voltametric determination of CGA in plant extracts. DMC was synthesized through a simple method, using nanosilicon as hard template, sucrose as carbon source, and $\mathrm{KNO}_{3}$ as flaw producing agent. The characteristics of the modified electrode (IL/DMC/PE) were evaluated through $\mathrm{CV}$, electrochemical impedance spectroscopy and chronocoulometry. The proposed sensor showed remarkable efficiency related to the electrochemical reaction of CGA in aqueous solutions. Moreover, the electrocatalytic behavior was studied through SWV, due to the better sensitivity and resolution of this method in comparison with those of CV. 


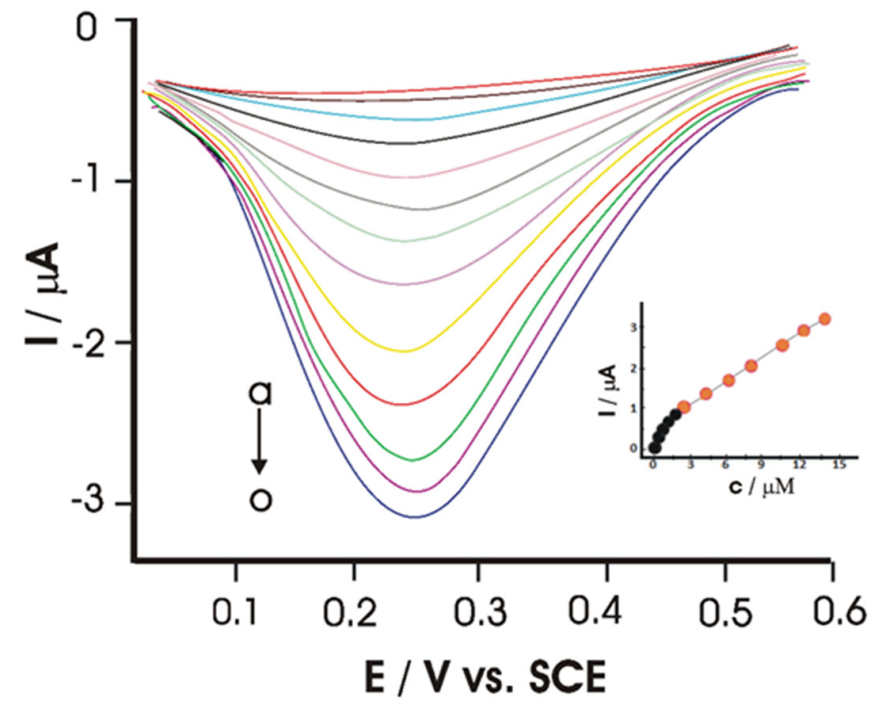

Figure 7. Differential pulse voltammograms at $\mathrm{UiO}-66-\mathrm{NH}_{2} / \mathrm{TiO}_{2} / \mathrm{GCE}$ for different concentrations of chlorogenic acid in pH 6.0 PBS (from a to o) 0.01, 0.03, 0.05, 0.07, 0.1, 0.3, 0.5, 0.7, 1.0, 3.0, 5.0, 7.0, 10, 13 and $15 \mu \mathrm{mol} \cdot \mathrm{L}^{-1}$. The inset shows the relationship between the peak current and the chlorogenic acid concentration. Adapted from [61].

Figure 8 shows the cyclic voltammograms obtained and the calibration curve for various concentrations of CGA. In optimum conditions, the currents of the anodic peak increased linearly with the CGA concentration, in the range $0.02-2.5 \times 10^{-6} \mathrm{~mol} \cdot \mathrm{L}^{-1}$, the limit of detection obtained being $1 \times 10^{-8} \mathrm{~mol} \cdot \mathrm{L}^{-1}$.

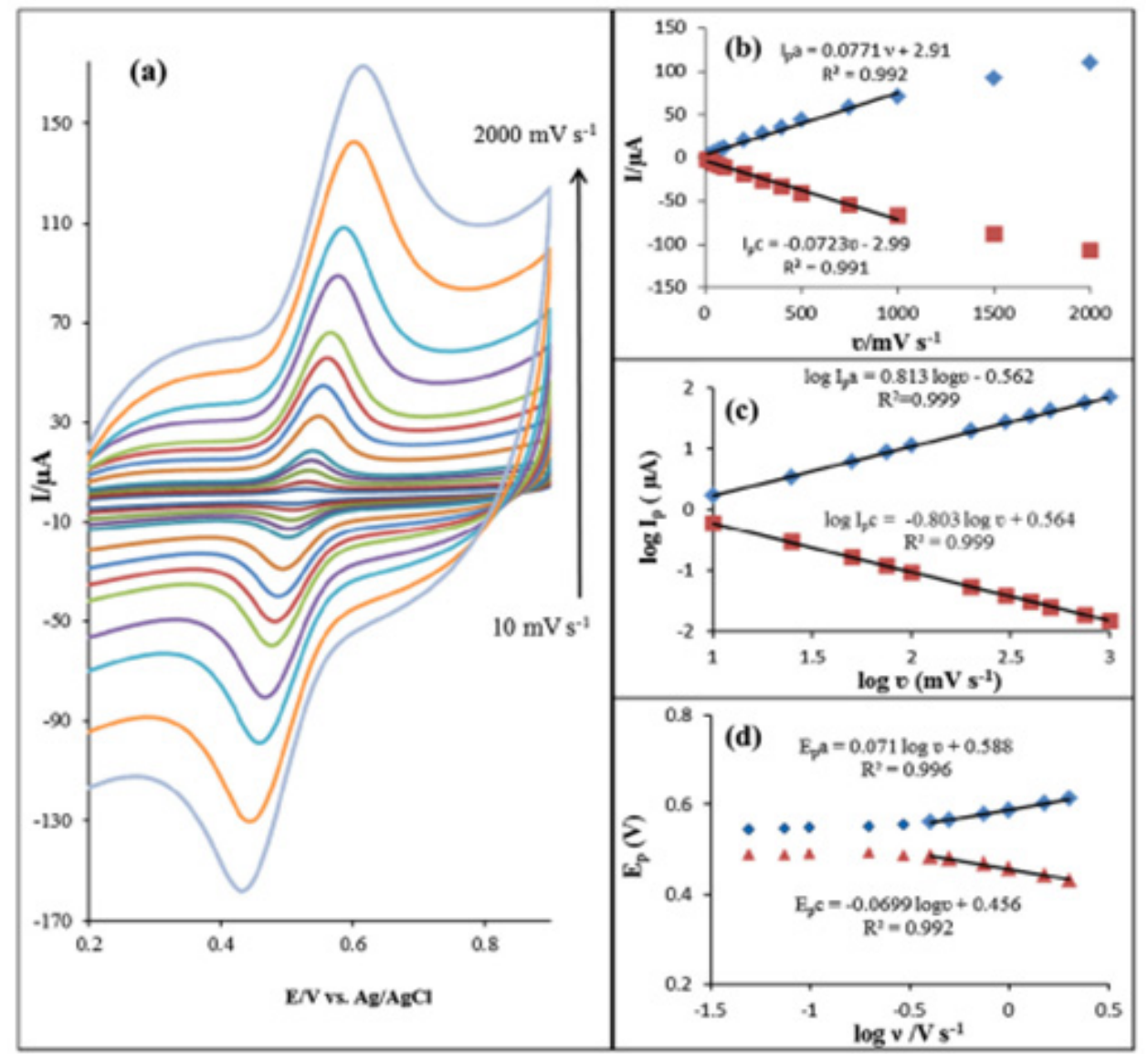

Figure 8. (a) CV responses of the modified electrode in Britton-Robinson buffer solution ( $\mathrm{pH}$ 2) at 
scan rates (inner to outer) 10, 25, 50, 75, 100, 150, 200, 300, 400, 500, 750, 1000, 1500 and $2000 \mathrm{mV} \cdot \mathrm{s}^{-1}$. (b) The plot of anodic and cathodic peak current vs. scan rate. (c) The plot of anodic and cathodic peak current vs. logarithm of scan rate and (d) the variation of anodic and cathodic potential vs. logarithm of scan rate. Published from [62] with the permission of the publisher.

The relative standard deviation of five successive measurements with the same electrode toward $1 \times 10^{-6} \mathrm{~mol} \cdot \mathrm{L}^{-1} \mathrm{CGA}$ was approximately $3 \%$, suggesting good repeatability of the studied sensor. The long-term stability of the modified electrode was also verified, the current intensities following the measurements made for $1 \times 10^{-6} \mathrm{~mol} \cdot \mathrm{L}^{-1} \mathrm{CGA}$ remaining at $95 \%$ of its initial value after a month of storage at room temperature.

The applicability of the sensor studied was evaluated by determining the CGA content in two plant extracts. The results obtained were satisfactory, with analytic recovery in the 98.6-105.8\% range, which indicates that the proposed sensor could be efficiently applied in reliably determining CGA from plant extracts [62].

Another study was aimed to prepare the TAPB-DMTP-COFs composite doped with gold nanoparticles (TAPB, 1,3,5-tri(4-aminophenyl)benzene; DMTP, 2,5-dimethoxyterephaldehyde; COFs, covalent organic frameworks), then used to develop a new electrochemical sensor. This indicated a good electrocatalytic activity on CGA oxidation in phosphate buffer solution at $\mathrm{pH}$ 7.0. The electrochemical sensor obtained showed a linearity range between $1.00 \times 10^{-8}$ and $4.00 \times 10^{-5} \mathrm{M}$, with limit of detection $9.50 \times 10^{-9} \mathrm{M}$. According to the method proposed, the sensor was applied for determining CGA from coffee samples, fruit juices and plant extracts, the analytical recovery being $99.20-102.50 \%$. The results of CGA determination were according to those obtained through the HPLC method [63].

R. Chokkareddy et al. developed a new sensor (LGN-MWCNTs-CuONPs-GCE) to detect CGA in coffee samples, modifying the glassy carbon electrode with nanocomposites based on multi-walled carbon nanotubes (MWCNTs), copper oxide nanoparticles (CuONPs) and a polymer-lignin (LGN). Using CV, the quasi-reversible nature of the process was highlighted, as well as the fact that it is controlled by the adsorption of electroactive species on the surface of the sensor. Nanoparticles and synthesized nanocomposites were characterized through FTIR, transmission electronic microscopy (TEM) and X-ray diffraction analyses (XRD). DPV was applied and the anodic peak was used in the quantitative determination of CGA. The sensor proposed showed linear responses in the $5 \mu \mathrm{M}$ and $50 \mu \mathrm{M}$ range, the limit of detection (LOD) being $0.0125 \mu \mathrm{M}$, and the limit of quantification (LOQ) $0.2631 \mu \mathrm{M}$.

The LGN-MWCNTs-CuONPs-GCE sensor was then applied to detect CGA in coffee samples, with the analytical recoveries varying from 97 to $106 \%$. Thus, the sensor developed was successfully used to analyze the CGA content in these samples. Moreover, the electrophile, nucleophile reactions of CGA and the studies on CGA docking were carried out to better understand the redox mechanisms; they were supported by calculations of the density-functional theory [64].

Another study, carried out in 2020, aimed to develop a new voltammetric method for CGA detection using a glassy carbon electrode modified with niobium nanoparticles (NbNPs) and multi-walled carbon nanotubes. To characterize the electrode sensitive material, analytical techniques_-such as energy dispersion X-ray analysis (EDX), scanning electronic microscopy (SEM) and X-ray diffraction (XRD) spectroscopy-were used. Figure 9 shows the scheme for achieving the sensor and for use in the voltammetric analysis of the samples.

Square wave voltammetry (SWV) was also used to determine the linear range and the limit of detection (LOD). What was observed was that the intensities of the peaks were linear with the CGA concentration, in the range $2.0 \times 10^{-9} \mathrm{M}$ and $2.0 \times 10^{-6} \mathrm{M}$, with LOD $2.0 \times 10^{-9} \mathrm{M}$. This value of the LOD obtained indicated that the voltammetric method proposed, using a NbNPs/CNTs/GCE sensor, was extremely sensitive to determine CGA as compared to other LOD values obtained with other electrodes $[51,65,66]$. 


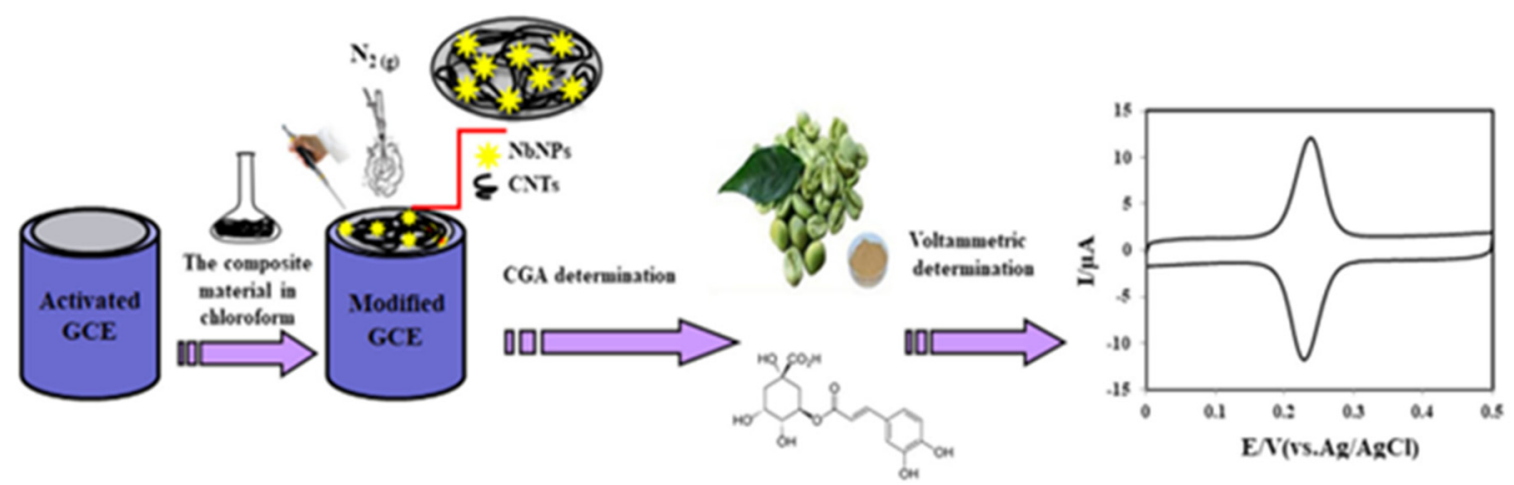

Figure 9. A simple illustration for the preparation of the platform and its application in electroanalysis. Published from [67] with the permission of the publisher.

To highlight the possible mechanism of the redox process, CVs with different scan rates were used, the response obtained being linear with the scan rates, in the $50-250 \mathrm{mV} / \mathrm{s}$ range. This suggests that the process is controlled by the adsorption of the species, which are active on the surface of the electrode (Figure 10).
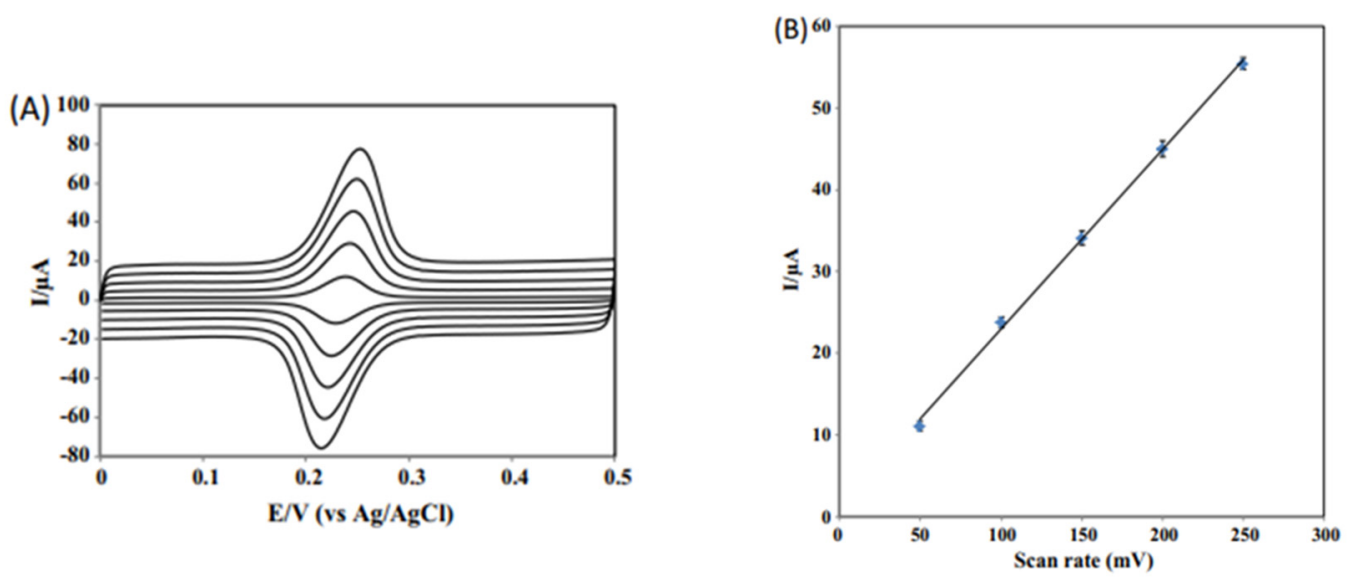

Figure 10. (A) CVs of $1.0 \times 10^{-7} \mathrm{M} \mathrm{CGA}$ at NbNPs/CNTs/GCE in $0.1 \mathrm{M} \mathrm{PBS}$ at pH 7.0. Scan rate: $50 \mathrm{mV} / \mathrm{s}, 100 \mathrm{mV} / \mathrm{s}$, $150 \mathrm{mV} / \mathrm{s}, 200 \mathrm{mV} / \mathrm{s}, 250 \mathrm{mV} / \mathrm{s}$ (bottom to top). (B) A plot of anodic peak currents of CGA versus scan rates. Published from [67] with the permission of the publisher.

Subsequently, the sensor proposed was used to determine CGA in green coffee samples, in tomato juice and carbonated drinks. The quantity of CGA obtained was $19.1 \mathrm{mg} / \mathrm{g}$ in the coffee beans, $11.4 \mathrm{mg} / 100 \mathrm{~mL}$ for the tomato juice, and $1.84 \mathrm{mg} / 100 \mathrm{~mL}$ for the carbonated drinks. The analytical recoveries of $99 \%$ and $101.2 \%$ demonstrated that the method proposed is accurate for determining CGA in real samples [67].

Detecting CGA in clinical samples for studies on metabolic kinetics is a challenging mission due to low concentration and lack of sensitive analytical methods. Taking this analytical issue into account, a porous pencil lead electrode (PLE) was used to detect CGA, using SWV as electroanalytical method. Sensitivity was significantly increased due to CGA accumulation in the porous structure of the electrode. In optimum conditions, CGA concentration was linear in the range $7.7 \times 10^{-8}-7.7 \times 10^{-6} \mathrm{M}$, with limit of detection $4.5 \times 10^{-9} \mathrm{M}$. Later, the electrode was used to determine CGA in human urine, with analytical recoveries between $89.6 \%$ and $105.5 \%$. This highlighted the precision of the method, recommended for use in the rapid and sensitive detection of CGA in human urine samples [68].

In a recent study, three screen-printed electrodes-namely the screen-printed carbon electrode (C-SPE), the screen-printed carbon electrode modified with graphene (GPH-SPE), and the screen-printed carbon electrode modified with graphene and gold nanoparticles 
(GPH-GNP-SPE) - were used to study the electrochemical behavior of CGA in watery solutions, the method of detection employed being CV.

Cyclic voltammograms of the $10^{-3} \mathrm{~mol} / \mathrm{L}$ CGA solution were recorded. The $10^{-1} \mathrm{M}$ $(\mathrm{pH}=7.0)$ phosphate buffer solution was used as a supporting electrolyte. To obtain a stable response of the sensor, five cycles were necessary in the optimized potential range (from $-0.4 \mathrm{~V}$ to $0.7 \mathrm{~V}$ ). The cyclic voltammograms presented in Figure 11 were obtained after signal stabilization.
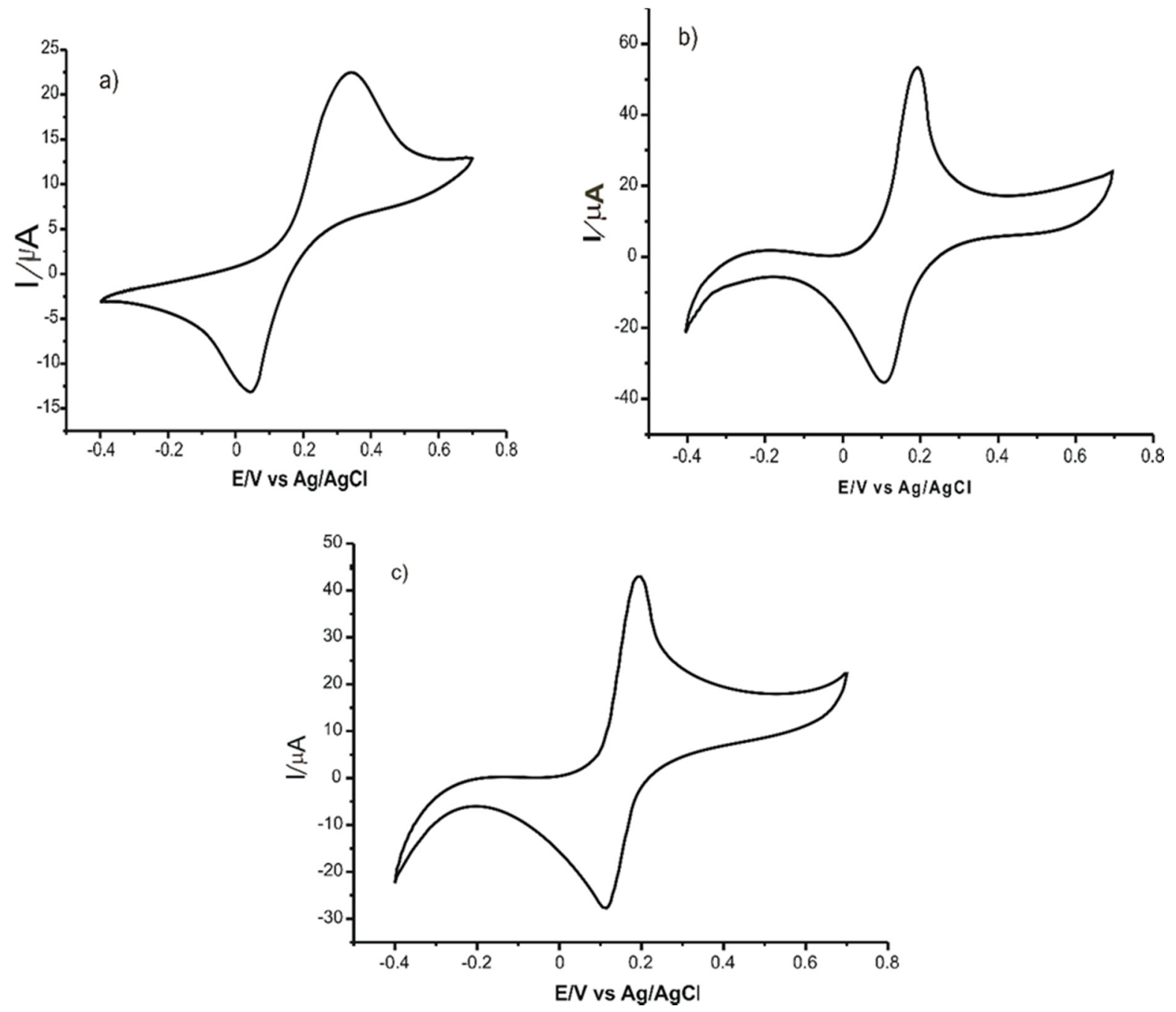

Figure 11. CVs of: (a) C-SPEs, (b) GPH-SPE and (c) GPH-GNP-SPE immersed in $10^{-3}$ M CGA solution (support electrolyte $10^{-1} \mathrm{M}$ PBS solution). Scan rate $0.1 \mathrm{~V} \cdot \mathrm{s}^{-1}[58]$.

Further, the limits of detection and the limits of quantification were determined for all three electrodes studied, and the values obtained are shown in Table 2.

Table 2. LOD and LOQ values of CGA for all three electrodes [54].

\begin{tabular}{ccc}
\hline Electrode & LOD (M) & LOQ (M) \\
\hline C-SPE & $6.50 \times 10^{-7}$ & $2.16 \times 10^{-6}$ \\
GPH-SPE & $0.73 \times 10^{-7}$ & $2.45 \times 10^{-6}$ \\
GPH-GNP-SPE & $0.62 \times 10^{-7}$ & $1.94 \times 10^{-7}$ \\
\hline
\end{tabular}

Low values of the limit of detection and of the limit of quantification were due to the sensors used in the study, which demonstrated the feasibility of the voltammetric method for analyzing CGA in real samples such as nutraceutical products. Thus, the next 
stage of the study involved the quantitative determination of CGA in three nutraceutical products. Two methods were used: CV for determination and FTIR (spectrometric method) for validation of the voltammetric method's accuracy. The results obtained were very close to those obtained through the standard analysis method, and the confidence level was $99 \%[58]$.

The electrochemical sensors achieved and used to analyze CGA were based on nanomaterials, conductive organic polymers and nanocomposites based on carbon structures decorated with semiconductive particles (gold nanoparticles, copper oxide nanoparticles, niobium nanoparticles). They were all used successfully in the sensitive and precise analysis of CGA, especially in vegetable products.

However, some facts reduce the applicability of the sensors in CGA analysis. On one hand, the inactivation of the electrode active surface area due to the adsorption of macromolecules or of reaction products greatly affect the electrode response stability. Moreover, coexisting components, which may be present in concentrations much larger than the analytes, may severely interfere in the determination of the targeted compound. Complicated sample pretreatments are often employed to eliminate or separate interfering components.

These disadvantages can often be controlled by changing the surface of the sensors using mediators and/or enzymes to improve quantitative measurements and also to adapt the electrode to specific responses to certain application. Electrochemical biosensors represent very interesting devices for on-line monitoring beside single-detection uses. The analytical performances of the electrochemical biosensors in CGA analysis, as well as their key fabrication details, are reported in the next section.

\subsubsection{Electrochemical Biosensors Used in CGA Detection}

At present, a variety of enzymes belonging to the oxidoreductase class (tyrosine [69], laccase [70] and peroxidase [71]) are used in the electrochemical detection of phenolic compounds and in evaluating their antioxidant activity through biochemical oxidation followed by electrochemical reduction [72].

These enzymes may be considered functional components of the electrochemical sensors. However, the substrate recognition process is based on their mechanism of action. Consequently, they also play the role of recognition elements for target cells, and the substrate selectivity leads to the detection of specific classes of phenolic compounds or other chemical compounds. Their use on the electrode's surface is not a novelty, but necessitates solving certain typical issues which result from the obligation of correctly immobilizing the enzyme, from the compatibility with more types of materials and from the modifications of the conductive properties of the active surface [73].

The schematic representation of preparing a biosensor using the enzyme is shown in Figure 12 [74].

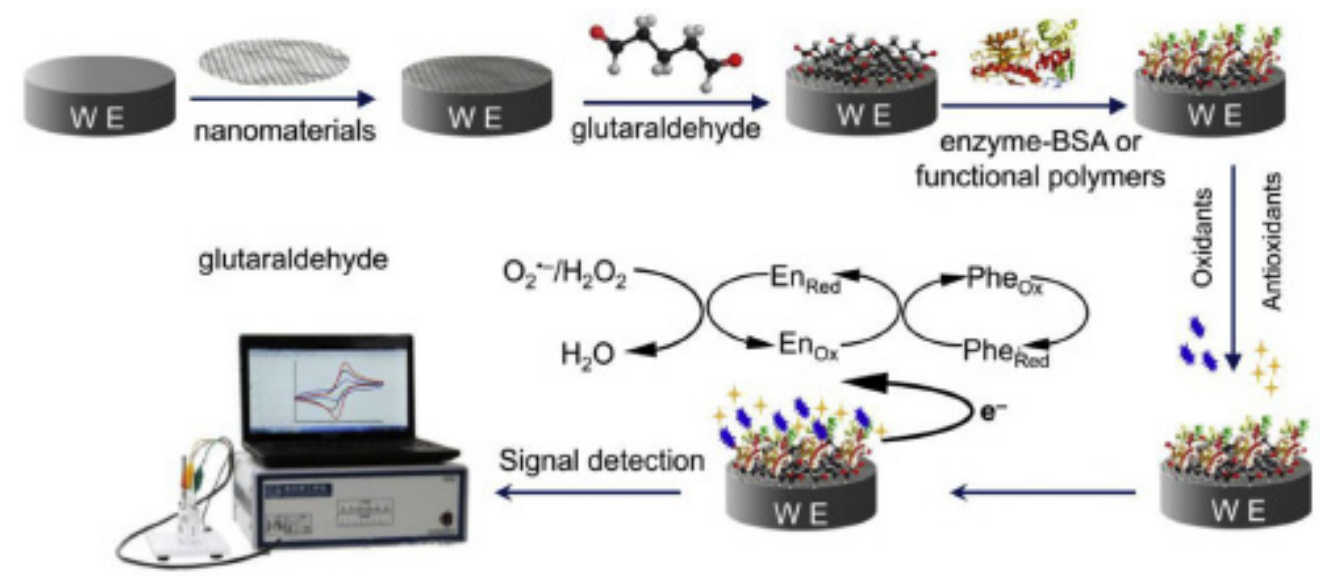

Figure 12. Schematic illustration of the preparation of modified enzyme-based electrode. Published from [74] with the permission of the publisher. 
A study carried out in 2008 described the development of two biosensors for determining CGA through immobilizing homogenized fresh bean sprout (Vigna radiata) in chitosan microspheres (biosensor I) and silicon microspheres (biosensor II), crosslinked with glutaraldehyde and epichlorohydrin. The bean sprout tissue acts like a source of peroxidase which, in the presence of hydrogen peroxide, catalyzes the oxidation of CGA. The CGA concentration was linear in the range $4.89 \times 10^{-6}-3.20 \times 10^{-4}$ for biosensor I, and in the range $4.89 \times 10^{-6}-4.85 \times 10^{-5}$ for biosensor II. The limits of detection obtained for the two biosensors were $8.02 \times 10^{-7} \mathrm{M}$ for biosensor I and $8.52 \times 10^{-7} \mathrm{M}$ for biosensor II. Last but not least, the two biosensors demonstrated good long-term stability (4 months, 300 determinations) and reproducibility, with a relative standard deviation of $3.5 \%$ for biosensor I and $1.5 \%$ for biosensor II. The CGA recoveries from four coffee samples varied between $96.5 \%$ and $102.6 \%$ (biosensor I), and between $91.3 \%$ and $115.5 \%$ (biosensor II). Thus, the results obtained for determining CGA in real samples using the proposed biosensors and those obtained through using the capillary electrophoresis method were in accordance, at a confidence level of $95 \%$ [75].

One year later, in 2009, a study on constructing a biosensor based on ionic liquid, 1-n-butil-3-methylimidazole hexafluorophosphate containing iridium dispersed nanoparticles $\left(\mathrm{Ir}-\mathrm{BMI}_{\mathrm{P}} \mathrm{F}_{6}\right)$ and polyphenol oxidase (PPO) was carried out. This enzyme was obtained from sugar apple (Annona squamosa), immobilized in crosslinked ionic chitosan with oxalate. The biosensor obtained was used to determine CGA through square wave voltammetry.

The positive charged amino groups of chitosan can react with the negative charged oxalate through electrostatic attraction to form ionically crosslinked networks. Figure 13 shows the schematic representation of immobilizing PPO in the vegetal material (sugar apple) in the ionically crosslinked chitosan, obtaining the proposed biosensor with high stability and durability. Polyphenol oxidase catalyzes CGA oxidation at the corresponding o-quinone, which is electrochemically reduced, the same compound being obtained at $+0.25 \mathrm{~V}$ vs. $\mathrm{Ag} / \mathrm{AgCl}$. In these experimental conditions, the response of biosensor was linear with the CGA concentration in the range $3.48 \times 10^{-6}$ and $4.95 \times 10^{-5} \mathrm{~mol} \mathrm{~L}^{-1}$, with a limit of detection of $9.15 \times 10^{-7} \mathrm{~mol} \mathrm{~L}^{-1}$. Later, the biosensor was applied for CGA determination in decaffeinated organic coffee samples, and the results obtained were compared to those obtained by using the capillary electrophoresis method. The study on CGA recovery in these samples gave values between $93.2 \%$ and $105.7 \%$. Therefore, immobilizing enzyme in biocompatible chitosan, together with Ir-BMI.PF ${ }_{6}$, applied to determine CGA in coffee beans, proved to be a simple and efficient analytical method [76].

Another study consisted in developing a network of sensors based on a double screen-printed carbon electrode to simultaneously determine CGA and caffeine. One of the working electrodes was modified with platinum nanoparticles, reduced graphene oxide and laccase (C-SPE/Pt-NPs/RGO/Lac-biosensor) to determine CGA, while the second working electrode was modified with reduced graphene oxide and Nafion (C-SPE/RGO/Nafionsensor) and was used to determine caffeine. Cyclic voltammetry was the method used to characterize and optimize the sensor array, while chronoamperometry was used to study the bioelectrocatalytic response. The C-SPE/Pt-NPs/RGO/Lac biosensor, used to detect CGA, had a sensitivity of $0.02 \mu \mathrm{A} / \mu \mathrm{M}$ and a limit of detection of $2.67 \mu \mathrm{M}$, while the C-SPE/RGO/Nafion sensor, used to detect caffeine, had a sensitivity of $1.38 \mu \mathrm{A} / \mu \mathrm{M}$ and a limit of detection of $0.22 \mu \mathrm{M}$. The sensor array developed was later used to determine the two phenolic compounds in real coffee samples. It could be concluded that, due to its simplicity, feasibility and accessibility, the sensor array developed could represent the basis for a valuable analytical tool, capable of analyzing both the CGA content and the content of caffeine in coffee samples, thus providing important information about the phytochemical composition of samples [77]. 


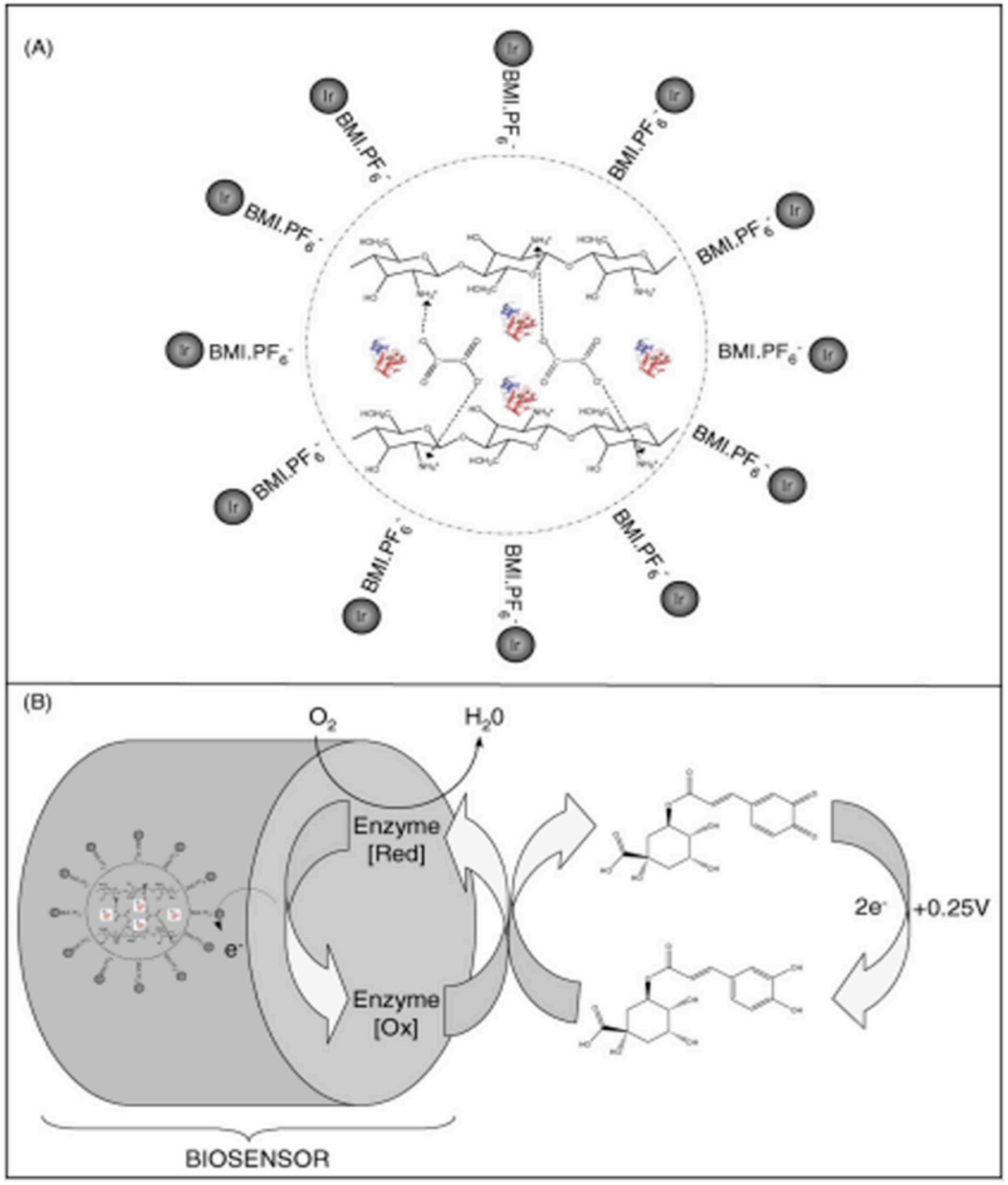

Figure 13. Schematic representation of (A) immobilization of PPO on chitosan crosslinked with oxalate and (B) reaction involving chlorogenic acid on the surface of the biosensor. Published from [76] with the permission of the publisher.

Similar to the previous study, another paper described the development of amperometric biosensors based on glassy carbon electrodes modified with graphene oxide and MWCNTs. The two biosensors were achieved with the aid of two enzymes, namely tyrosine (Tyr) and laccase (Lac). Before the deposition of the enzyme, the graphene oxide was reduced through the electrochemical method, using CV. The immobilization of the enzyme on the surface of the modified electrode was optimized using various agents (bovine serum albumin and glutaraldehyde as reticulation agent, chitosan and Nafion). The conditions for manufacturing and storing biosensors were established to obtain a good enzyme retention, high sensitivities and durable devices.

Figure 14 shows the relevant electrochemical responses of the biosensors. It can be observed that, for the biosensor based on laccase, one pair of symmetrical redox peaks is highlighted, while for the biosensor based on tyrosine, two pairs of redox peaks are highlighted. This may be attributed to the carbon nanomaterial, which favors the transfer of electrons between the active centers of the tyrosine and the electrode. 

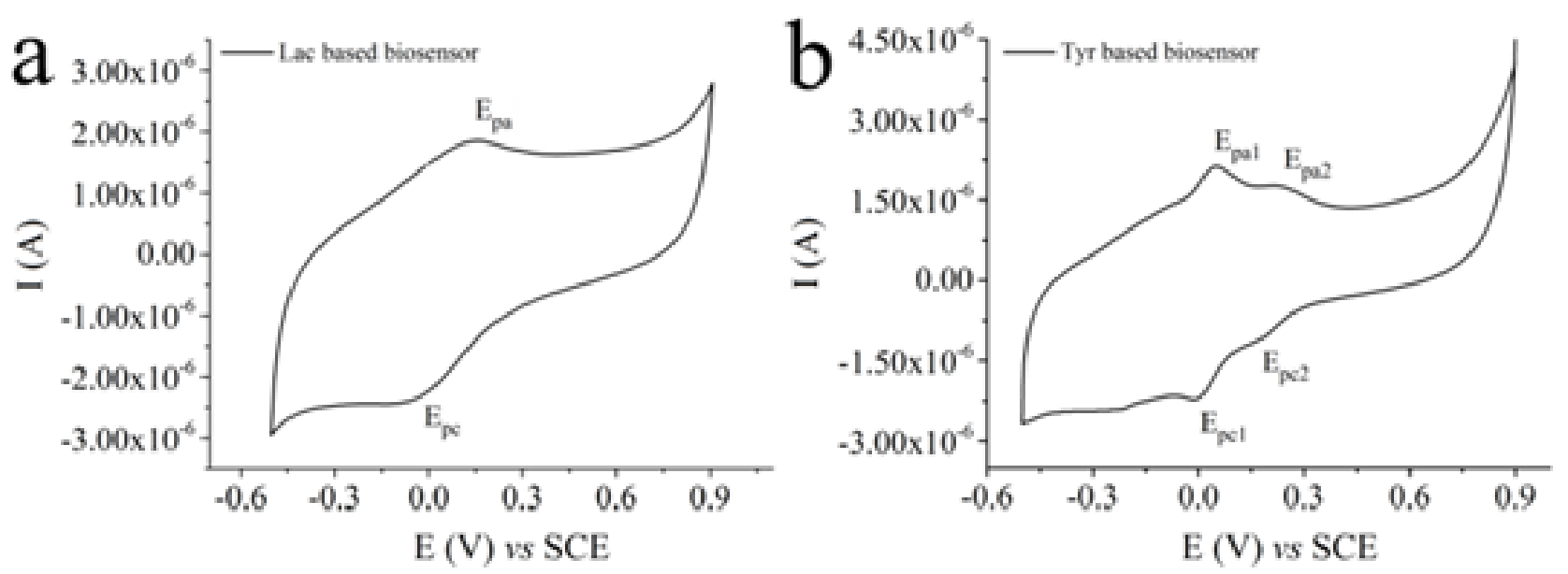

Figure 14. $\mathrm{CV}$ characterizations recorded in $0.1 \mathrm{M}$ acetate buffer, $\mathrm{pH} 4.5$ for a biosensor obtained by casting $10 \mu \mathrm{L}$ of a suspension containing $8 \mathrm{mg} \cdot \mathrm{mL}^{-1} \mathrm{Lac}(\mathbf{a})$, and in $0.05 \mathrm{M}$ PBS, pH 6.5, for a biosensor obtained by casting $10 \mu \mathrm{L}$ of a suspension containing $6 \mathrm{mg} \cdot \mathrm{mL}^{-1} \mathrm{Tyr}$, working under Ar atmosphere (b). Scan rate: $0.005 \mathrm{~V} \cdot \mathrm{s}^{-1}$. Published from [78] with the permission of the publisher.

The limit of detection calculated from the calibration curve was $0.3 \mu \mathrm{M}$. The biosensors thus obtained were used to determine the catechol of other polyphenols also, namely pyrogallol, epicatechin, gallic acid, 1,2-dihydroxibenzoic acid, caffeic acid, chlorogenic acid, rutin, catechin and dopamine. Finally, their practical applicability was demonstrated through estimating the total concentration of polyphenols in the juice sample, expressed as epicatechin equivalents [78].

The development of a new, ultrasensitive electrochemical biosensor to determine hydroquinone and CGA was described by F. Tulli et al. The biosensor was prepared through horseradish peroxidase immobilization (HRP) on nanohydrogels from Laponite, gold nanoparticle (AuNP) and copolymerized vinilbenziltrietilammonium polication with vinilbenziltiaminic groups. The structure and the active site of the enzyme were not modified on immobilization, which was determined through UV-Vis spectroscopy and FTIR. The biosensor showed remarkable electroanalytical properties for detecting CGA and hydroquinone, with a limit of detection of $1.6 \pm 0.2 \mathrm{nM}$ and $2.7 \pm 0.1 \mathrm{nM}$, respectively. The biosensors were tested successfully to quantify the total content of polyphenols in green tea and yerba mate infusions and the results were comparable to those of the Folin-Ciocalteu method. The biosensor obtained had remarkable advantages due to its ultra-sensitivity, the small volumes of necessary samples and the short times needed for detection-all contributing to improving the analytical applicability [79].

E. Akyuz et al. proposed the development of a biosensor based on proteins, which can measure pro-oxidant activities of phenolic compounds (Figure 15). To obtain the biosensor, proteins from egg white were precipitated with calcium chloride to obtain a complex of insoluble calcium proteins. This biosensor was used to determine the pro-oxidant activity induced by $\mathrm{Cu}$ (II) of antioxidants such as gallic acid, catechin, epicatechin, quercetin, CGA, myricetin and ascorbic acid. The analysis involved $\mathrm{Cu}(\mathrm{II})$ ion reduction at $\mathrm{Cu}(\mathrm{I})$ by the antioxidant compounds (which produce simultaneous reactive oxygen species), followed by linking the $\mathrm{Cu}(\mathrm{I})$ formed to the solid biosensor. $\mathrm{Cu}(\mathrm{I})$ linked to the protein is an indicator of the pro-oxidant activity of antioxidants on proteins, colorimetric determined at $450 \mathrm{~nm}$ with neocuproine $(\mathrm{Nc})$. The method was applied to synthetic mixtures and plant infusions (sage, green tea, mint and rosemary). The advantages of this biosensor were related to the low costs, the possibilities of large-scale production, and use over a longer period of time [80]. 


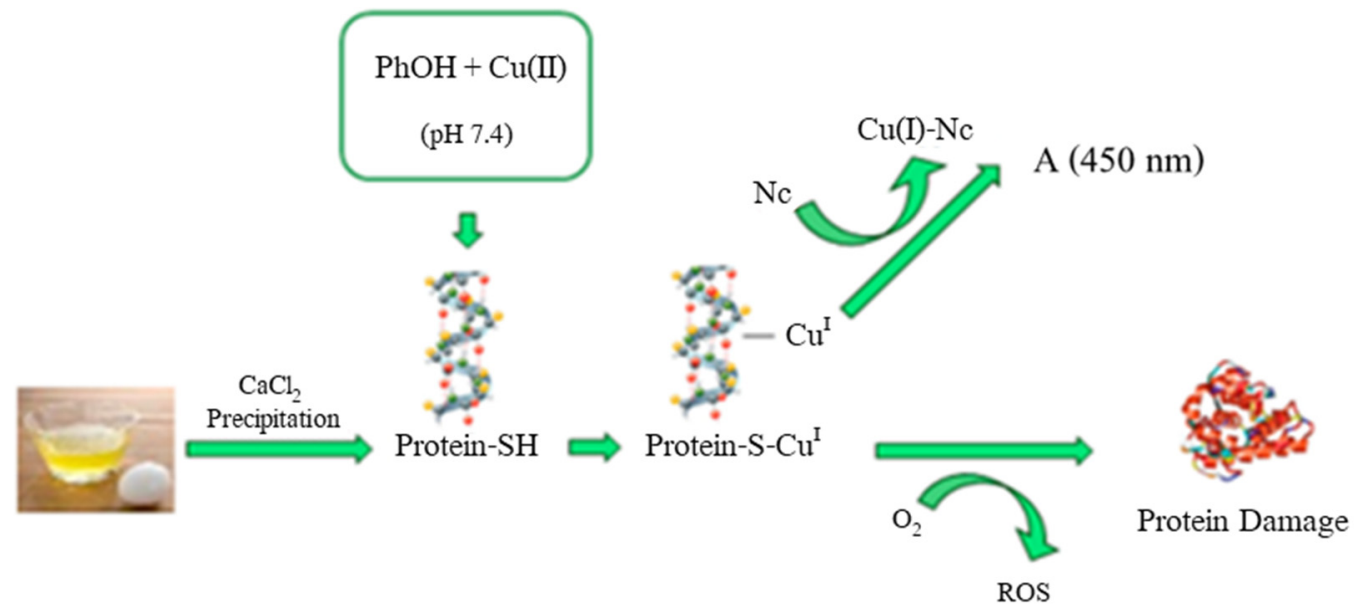

Figure 15. Schematic diagram of the proposed total pro-oxidant activity (TPA) assay using protein-based sensor. Reprinted with permission from [80]. Copyright 2021 American Chemical Society.

The biosensors used to determine CGA were mainly based on enzymes (polyphenol oxidase, laccase, tyrosine and peroxidase) and on nanocomposite materials (platinum nanoparticles, gold nanoparticles, iridium nanoparticles), which facilitated the sensitive and selective detection from complex samples.

As in the case of sensors, enzymatic biosensors could have some drawbacks related to loss of enzymatic activity upon immobilization of enzyme and during the use of biosensor, as well as difficulties in recovering biosensor activity. These limitations can be avoided by using optimal enzyme immobilization techniques [81].

Enzyme immobilization on the surface of the electrodes is not a novel technique, but calls for the resolution of typical problems arising from the need of correct immobilization, compatibility with the advanced materials used in the development of the biosensor, changes in the conductive properties of the surface, and inactivation by inhibition at the catalytic site level [1].

The sensitive materials and the analytical features for the principal electrochemical sensors and biosensors used for CGA detection, most of them detailed above in this review, are summarized in Table 3.

Table 3. Main electrochemical sensors and biosensors used for CGA detection.

\begin{tabular}{|c|c|c|c|c|c|}
\hline Sensitive Material & $\begin{array}{l}\text { Detection } \\
\text { Technique }\end{array}$ & $\begin{array}{c}\text { Linear Range } \\
\mu \mathrm{mol} \cdot \mathrm{L}^{-1}\end{array}$ & $\begin{array}{c}\text { LOD } \\
\mu \mathrm{mol} \cdot \mathrm{L}^{-1}\end{array}$ & Real Samples & Ref. \\
\hline \multicolumn{6}{|c|}{ Sensors } \\
\hline $\mathrm{MIS} / \mathrm{Au}$ & DPV & $5 \times 10^{-1}-12$ & $1.48 \times 10^{-1}$ & $\begin{array}{l}\text { Coffee } \\
\text { Tea }\end{array}$ & [59] \\
\hline MWCNTs/SPE & CV, DPV & $4.8 \times 10^{-1}-44.59$ & $3.4 \times 10^{-1}$ & Coffee beans & [52] \\
\hline $\begin{array}{l}\mathrm{Fe}_{3} \mathrm{O}_{4} @ \mathrm{MIL}- \\
100(\mathrm{Fe}) / \mathrm{GCE}\end{array}$ & EIS, CV & $1 \times 10^{-1}-460$ & $5 \times 10^{-2}$ & $\begin{array}{l}\text { Apple } \\
\text { Coffee }\end{array}$ & [60] \\
\hline UiO-66- $\mathrm{NH}_{2} / \mathrm{TiO}_{2}$ & CV, DPV & $1 \times 10^{-2}-13.0$ & $7 \times 10^{-3}$ & $\begin{array}{l}\text { Coffee } \\
\text { Tea }\end{array}$ & [61] \\
\hline $\mathrm{IL} / \mathrm{DMC} / \mathrm{PE}$ & CV, EIS, SWV & $2 \times 10^{-2}-2.5$ & $1 \times 10^{-2}$ & $\begin{array}{c}\text { Herbal extracts of } \\
\text { Calendula } \\
\text { ocinalis and Echinacea } \\
\text { purpurea }\end{array}$ & [62] \\
\hline $\begin{array}{l}\text { TAPB-DMTP- } \\
\text { COFs/AuNPs }\end{array}$ & CV, DPV & $1 \times 10^{-2}-40$ & $9.5 \times 10^{-3}$ & $\begin{array}{c}\text { Coffee } \\
\text { Apple } \\
\text { Honeysuckle }\end{array}$ & [63] \\
\hline
\end{tabular}


Table 3. Cont.

\begin{tabular}{|c|c|c|c|c|c|}
\hline Sensitive Material & $\begin{array}{l}\text { Detection } \\
\text { Technique }\end{array}$ & $\begin{array}{l}\text { Linear Range } \\
\mu \mathrm{mol} \cdot \mathrm{L}^{-1}\end{array}$ & $\begin{array}{c}\text { LOD } \\
\mu \mathrm{mol} \cdot \mathrm{L}^{-1}\end{array}$ & Real Samples & Ref. \\
\hline \multicolumn{6}{|c|}{ Sensors } \\
\hline $\begin{array}{l}\text { LGN-MWCNTs- } \\
\text { CuONPs-GCE }\end{array}$ & CV, DPV & $5-50$ & $1.25 \times 10^{-2}$ & Coffee & {$[64]$} \\
\hline NbNPs/CNTs/GCE & CV, SWV & $2 \times 10^{-3}-2$ & $8.2 \times 10^{-4}$ & $\begin{array}{l}\text { Coffee } \\
\text { Tomato } \\
\text { Drinks }\end{array}$ & [67] \\
\hline PLE & SWV & $7.7 \times 10^{-2}-7.7$ & $4.5 \times 10^{-3}$ & $\begin{array}{l}\text { Clinical samples } \\
\text { (Human urine) }\end{array}$ & [68] \\
\hline GPH-GNP-SPE & $\mathrm{CV}$ & $1 \times 10^{-1}-1.20$ & $6.2 \times 10^{-2}$ & $\begin{array}{c}\text { Nutraceutical products } \\
\text { based on Green Coffee } \\
\text { extract }\end{array}$ & [58] \\
\hline \multicolumn{6}{|c|}{ Biosensors } \\
\hline Bean sprout homogenate & SWV & $3.48-320$ & $8 \times 10^{-1}$ & Coffee & [75] \\
\hline Ir-BMI.PF 6 -PPO & SWV & $3.48-49.50$ & $9.1 \times 10^{-1}$ & Decaffeinated coffee & {$[76]$} \\
\hline $\begin{array}{c}\text { C-SPE/Pt- } \\
\text { NPs/RGO/Lacc }\end{array}$ & $\mathrm{CV}, \mathrm{CA}$ & $2.91-26.47$ & 2.67 & Coffee & [77] \\
\hline $\begin{array}{l}\text { GCE-CO-LAC- } \\
\text { MWCNTs }\end{array}$ & $\mathrm{CV}, \mathrm{CA}$ & $1-300$ & $3 \times 10^{-1}$ & Juice & [78] \\
\hline $\begin{array}{l}\mathrm{Lap} /\left\{\left[(\mathrm{VBT})(\mathrm{VBA})_{4}\right]^{4+}\right\} \\
\quad \approx 25 / \mathrm{AuNP} / \mathrm{HRP}\end{array}$ & CV, EIS & $1-120$ & $2.7 \times 10^{-3}$ & $\begin{array}{l}\text { Yerba mate } \\
\text { Green Coffee }\end{array}$ & [79] \\
\hline $\begin{array}{l}\mathrm{Cu}(\mathrm{II})-\mathrm{Nc} \text { protein-based } \\
\text { biosensor }\end{array}$ & $\begin{array}{l}\text { Colorimetric } \\
\text { detection }\end{array}$ & $25.0-250$ & 1.2 & $\begin{array}{l}\text { Herbal plant } \\
\text { extracts (sage, green tea, } \\
\text { mint, and marjoram) }\end{array}$ & [80] \\
\hline
\end{tabular}

MIS/Au—molecularly imprinted siloxane/Au sensor; DPV—differential pulse voltammetry; MWCNTs/SPE—multi-walled carbon nanotubes modified screen-printed electrode; $\mathrm{CV}$-cyclic voltammetry; $\mathrm{Fe}_{3} \mathrm{O}_{4} @ M I L-100(\mathrm{Fe}) / \mathrm{GCE}$ - superparamagnetic $\mathrm{Fe}_{3} \mathrm{O}_{4}$ core encapsulated into a metal-organic framework shell/glassy carbon electrode; EIS-electrochemical impedance spectroscopy; UiO-66$\mathrm{NH}_{2} / \mathrm{TiO}_{2}$-metal-organic frameworks/titanium dioxide; IL/DMC/PE-highly defective mesoporous carbon-ionic liquid paste electrode; SWV-square wave voltammetry; TAPB-DMTP-COFs / AuNPs-1,3,5-tris(4-aminophenyl)benzene- 2,5-dimethoxyterephaldehyde- covalent organic frameworks/gold nanoparticles; LGN-MWCNTs-CuONPs-GCE-lignin polymer-multiwalled carbon nanotubes-copper oxide nanoparticles-glassy carbon electrode; NbNPs/CNTs/GCE-glassy carbon electrode modified with niobium nanoparticles and multi-walled carbon nanotubes; PLE—pencil lead electrode; GPH-GNP-SPE—screen-printed electrode modified with graphene and gold nanoparticles; Ir-BMI.PF ${ }_{6}$-PPO-1-n-butyl-3-methylimidazolium hexafluorophosphate containing dispersed iridium nanoparticles (Ir-BMI.PF6) and polyphenol oxidase; C-SPE/Pt-NPs/RGO/Lacc-carbon screen-printed electrode modified with platinum nanoparticles, reduced graphene oxide and laccase; CA—chronoamperometry; GCE-CO-LAC-MWCNTs—glassy carbon electrode modified with graphene oxide, laccase and multi-walled carbon nanotubes; Lap $\left./\left\{(\mathrm{VBT})(\mathrm{VBA})_{4}\right]^{4+}\right\} \approx_{25} / \mathrm{AuNP} / \mathrm{HRP}$-horseradish peroxidase immobilization onto nanohydrogels made of laponite, gold nanoparticles and a vinylbenzyltriethylammonium polycation copolymerized with vinylbenzylthymine groups; $\mathrm{Cu}(\mathrm{II})-\mathrm{Nc}$ protein-based biosensor-protein-based solid prooxidant neocuproine biosensor for determining the $\mathrm{Cu}(\mathrm{II})$-induced prooxidant activity.

\section{Conclusions}

The development of sensors and biosensors created a wide variety of new detection possibilities, as well as opportunities for the efficient use of electroanalysis. They have remarkable analytical properties and can become useful tools in clinical diagnosis due to the fact that their determinations are simple, selective, rapid and sensitive.

The present paper reviewed the most recent research carried out in view of determining CGA using electrochemical sensors and biosensors. Electrochemistry is the first choice taken into consideration for determining CGA due to the redox activity of this phenolic compound. Nevertheless, the method is only partially satisfactory with regard to selectivity in recognizing target analytes. In recent years, electroanalysis has undergone major innovations following the development of new, organic or inorganic, nanostructured materials, and of composite systems which combine the sensitive properties of both classes of nanomaterials. Such systems have been applied on a large scale in the analysis of CGA 
content in various natural origin samples, from green coffee beans, grapes and wine, to spices and vegetables.

Most electroanalytical detection methods which involve sensors and biosensors have very good selectivity and sensitivity in detecting CGA, without involving stages of preparation in relation to the samples to be analyzed. There are, however, certain limitations concerning biosensors, linked to the contamination of the active surface or the reduced enzymatic activity. These limitations could be decreased or avoided through using complex nanocomposite materials which are resistant to contamination and are capable of acting synergistically with the enzyme.

Future studies carried out will have to focus on methods of developing biosensors, which avoid active surface contamination and interferences produced by the presence of chemical substances in the sample analyzed, and which allow the possibility to simultaneously detect more analytes, having applicability in various fields. Optical sensors are largely still to be developed and molecular imprinting could still play a major role in this field to improve selectivity. Studying the detection of CGA adsorption, metabolization and excretion in the human organism is another important direction for inter- and multi-disciplinary research to be carried out in the years to come. A very important aspect that must be taken into account in this field is related to the complex composition of real samples, especially biological fluids, in which different compounds can interact, reducing redox activity and thus the electrochemical signal.

Another future development direction in electrochemical biosensitivity will be the development of implantable sensors for continuous health monitoring. For this purpose, new nanomaterials need to be integrated into specific devices so as to achieve good longterm stability and limit contamination. New detection techniques, such as electrochemical scanning microscopy, spectroelectrochemistry or ultra-fast cyclic voltammetry should be implemented for real-time CGA monitoring.

Moreover, the development of commercial systems for the analysis and determination of CGA based on sensors which imply a series of artificial receptors-peptides and aptamers-as well as the development of detection systems which are compatible with electrophoretic or chromatographic systems have to be taken into serious consideration in the near future.

Author Contributions: Conceptualization, C.A. and I.G.M.; methodology, C.A.; writing—original draft preparation, I.G.M.; writing - review and editing, C.A.; supervision, C.A. All authors have read and agreed to the published version of the manuscript.

Funding: This research received no external funding. The publication fees for this article were supported by "Dunarea de Jos" University of Galati.

Institutional Review Board Statement: Ethical review and approval were waived for this study, due to the character of the publication based on reviewing the recent literature.

Informed Consent Statement: Not applicable.

Acknowledgments: The translation and linguistic review of the present article were made by Alexandru Praisler, member of the Research Center "Interface Research of the Original and Translated Text. Cognitive and Communicative Dimensions of the Message", Faculty of Letters, "Dunărea de Jos" University of Galați, Romania.

Conflicts of Interest: The authors declare no conflict of interest.

\section{References}

1. Forzato, C.; Vida, V.; Berti, F. Biosensors and Sensing Systems for Rapid Analysis of Phenolic Compounds from Plants: A Comprehensive Review. Biosensors 2020, 10, 105. [CrossRef]

2. Chaves, N.; Santiago, A.; Alías, J.C. Quantification of the Antioxidant Activity of Plant Extracts: Analysis of Sensitivity and Hierarchization Based on the Method Used. Antioxidants 2020, 9, 76. [CrossRef]

3. Pang, Y.; Ahmed, S.; Xu, Y.; Beta, T.; Zhu, Z.; Shao, Y.; Bao, J. Bound phenolic compounds and antioxidant properties of whole grain and bran of white, red and black rice. Food Chem. 2018, 240, 212-221. [CrossRef] 
4. Oliver, P.; Villem, A. (Eds.) Phenolic Compounds: Structure, Uses and Health Benefits; Chemistry Research and Applications; Nova Science Publishers: New York, NY, USA, 2017; ISBN 978-1-5361-2882-6.

5. Laganà, P.; Coniglio, M.; Fiorino, M.; Delgado, A.; Chammem, N.; Issaoui, M.; Gambuzza, M.; Iommi, C.; Haddad, M.; Delia, A. Phenolic Substances in Foods and Anticarcinogenic Properties: A Public Health Perspective. J. AOAC Int. 2020, 103, 935-939. [CrossRef]

6. Delgado, A.M.; Issaoui, M.; Chammem, N. Analysis of Main and Healthy Phenolic Compounds in Foods. J. AOAC Int. 2019, 102, 1356-1364. [CrossRef]

7. Munteanu, I.G.; Apetrei, C. Analytical Methods Used in Determining Antioxidant Activity: A Review. Int. J. Mol. Sci. 2021, 22, 3380. [CrossRef]

8. Scalbert, A.; Morand, C.; Manach, C.; Rémésy, C. Absorption and metabolism of polyphenols in the gut and impact on health. Biomed. Pharmacother. 2002, 56, 276-282. [CrossRef]

9. Balasundram, N.; Sundram, K.; Samman, S. Phenolic compounds in plants and agri-industrial by-products: Antioxidant activity, occurrence, and potential uses. Food Chem. 2006, 99, 191-203. [CrossRef]

10. Rashmi, H.B.; Negi, P.S. Phenolic acids from vegetables: A review on processing stability and health benefits. Food Res. Int. 2020, 136, 109298. [CrossRef]

11. Liu, Y.; Wang, P.; Chen, F.; Yuan, Y.; Zhu, Y.; Yan, H.; Hu, X. Role of plant polyphenols in acrylamide formation and elimination. Food Chem. 2015, 186, 46-53. [CrossRef]

12. Shahidi, F.; Naczk, M. Phenolics in Food and Nutraceuticals; First Issued in Paperback; CRC Press, Taylor \& Francis Group: Boca Raton, FL, USA; London, UK; New York, NY, USA, 2019; ISBN 978-0-367-39509-4.

13. Shao, Y.; Bao, J. Polyphenols in whole rice grain: Genetic diversity and health benefits. Food Chem. 2015, 180, 86-97. [CrossRef]

14. Bounegru, A.V.; Apetrei, C. Voltamperometric Sensors and Biosensors Based on Carbon Nanomaterials Used for Detecting Caffeic Acid-A Review. Int. J. Mol. Sci. 2020, 21, 9275. [CrossRef] [PubMed]

15. Soares, S. Phenolic acids as antioxidants. Rev. Nutr. 2002, 15, 71-81. [CrossRef]

16. King, A.; Young, G. Characteristics and Occurrence of Phenolic Phytochemicals. J. Am. Diet. Assoc. 1999, 99, 213-218. [CrossRef]

17. Matei, M.F.; Jaiswal, R.; Kuhnert, N. Investigating the Chemical Changes of Chlorogenic Acids during Coffee Brewing: Conjugate Addition of Water to the Olefinic Moiety of Chlorogenic Acids and Their Quinides. J. Agric. Food Chem. 2012, 60, 12105-12115. [CrossRef] [PubMed]

18. Li, G.; Wang, X.; Xu, Y.; Zhang, B.; Xia, X. Antimicrobial effect and mode of action of chlorogenic acid on Staphylococcus aureus. Eur. Food Res. Technol. 2014, 238, 589-596. [CrossRef]

19. Vereshchagina, Y.V.; Bulgakov, V.P.; Grigorchuk, V.P.; Rybin, V.G.; Veremeichik, G.N.; Tchernoded, G.K.; Gorpenchenko, T.Y.; Koren, O.G.; Phan, N.H.T.; Minh, N.T.; et al. The rolC gene increases caffeoylquinic acid production in transformed artichoke cells. Appl. Microbiol. Biotechnol. 2014, 98, 7773-7780. [CrossRef]

20. Santana-Gálvez, J.; Pérez-Carrillo, E.; Velázquez-Reyes, H.H.; Cisneros-Zevallos, L.; Jacobo-Velázquez, D.A. Application of wounding stress to produce a nutraceutical-rich carrot powder ingredient and its incorporation to nixtamalized corn flour tortillas. J. Funct. Foods 2016, 27, 655-666. [CrossRef]

21. Bhattacharyya, S.; Majhi, S.; Saha, B.P.; Mukherjee, P.K. Chlorogenic acid-phospholipid complex improve protection against UVA induced oxidative stress. J. Photochem. Photobiol. B 2014, 130, 293-298. [CrossRef]

22. Torres-Contreras, A.M.; Nair, V.; Cisneros-Zevallos, L.; Jacobo-Velázquez, D.A. Plants as biofactories: Stress-induced production of chlorogenic acid isomers in potato tubers as affected by wounding intensity and storage time. Ind. Crops Prod. 2014, 62, 61-66. [CrossRef]

23. Karunanidhi, A.; Thomas, R.; van Belkum, A.; Neela, V. In vitro antibacterial and antibiofilm activities of chlorogenic acid against clinical isolates of Stenotrophomonas maltophilia including the trimethoprim/sulfamethoxazole resistant strain. BioMed Res. Int. 2013, 2013, 392058. [CrossRef]

24. Niggeweg, R.; Michael, A.J.; Martin, C. Engineering plants with increased levels of the antioxidant chlorogenic acid. Nat. Biotechnol. 2004, 22, 746-754. [CrossRef] [PubMed]

25. Fiamegos, Y.C.; Kastritis, P.L.; Exarchou, V.; Han, H.; Bonvin, A.M.J.J.; Vervoort, J.; Lewis, K.; Hamblin, M.R.; Tegos, G.P. Antimicrobial and efflux pump inhibitory activity of caffeoylquinic acids from Artemisia absinthium against gram-positive pathogenic bacteria. PLoS ONE 2011, 6, e18127. [CrossRef]

26. Luo, H.-J.; Wang, J.-Z.; Chen, J.-F.; Zou, K. Docking study on chlorogenic acid as a potential H5N1 influenza A virus neuraminidase inhibitor. Med. Chem. Res. 2011, 20, 554-557. [CrossRef]

27. Meng, S.; Cao, J.; Feng, Q.; Peng, J.; Hu, Y. Roles of chlorogenic Acid on regulating glucose and lipids metabolism: A review. Evid.-Based Complement. Altern. Med. ECAM 2013, 2013, 801457. [CrossRef] [PubMed]

28. Zhao, Y.; Wang, J.; Ballevre, O.; Luo, H.; Zhang, W. Antihypertensive effects and mechanisms of chlorogenic acids. Hypertens. Res. Off. J. Jpn. Soc. Hypertens. 2012, 35, 370-374. [CrossRef]

29. Liang, N.; Kitts, D.D. Role of Chlorogenic Acids in Controlling Oxidative and Inflammatory Stress Conditions. Nutrients 2016, 8, 16. [CrossRef] [PubMed]

30. Lee, T.-K.; Kang, I.-J.; Kim, B.; Sim, H.J.; Kim, D.-W.; Ahn, J.H.; Lee, J.-C.; Ryoo, S.; Shin, M.C.; Cho, J.H.; et al. Experimental Pretreatment with Chlorogenic Acid Prevents Transient Ischemia-Induced Cognitive Decline and Neuronal Damage in the Hippocampus through Anti-Oxidative and Anti-Inflammatory Effects. Molecules 2020, 25, 3578. [CrossRef] [PubMed] 
31. Kassi, E.; Pervanidou, P.; Kaltsas, G.; Chrousos, G. Metabolic syndrome: Definitions and controversies. BMC Med. 2011, 9, 48. [CrossRef]

32. Lou, Z.; Wang, H.; Zhu, S.; Ma, C.; Wang, Z. Antibacterial activity and mechanism of action of chlorogenic acid. J. Food Sci. 2011, 76, M398-M403. [CrossRef]

33. Suzuki, A.; Kagawa, D.; Ochiai, R.; Tokimitsu, I.; Saito, I. Green coffee bean extract and its metabolites have a hypotensive effect in spontaneously hypertensive rats. Hypertens. Res. Off. J. Jpn. Soc. Hypertens. 2002, 25, 99-107. [CrossRef]

34. Stalmach, A.; Mullen, W.; Barron, D.; Uchida, K.; Yokota, T.; Cavin, C.; Steiling, H.; Williamson, G.; Crozier, A. Metabolite Profiling of Hydroxycinnamate Derivatives in Plasma and Urine after the Ingestion of Coffee by Humans: Identification of Biomarkers of Coffee Consumption. Drug Metab. Dispos. 2009, 37, 1749-1758. [CrossRef] [PubMed]

35. Renouf, M.; Guy, P.A.; Marmet, C.; Fraering, A.-L.; Longet, K.; Moulin, J.; Enslen, M.; Barron, D.; Dionisi, F.; Cavin, C.; et al. Measurement of caffeic and ferulic acid equivalents in plasma after coffee consumption: Small intestine and colon are key sites for coffee metabolism. Mol. Nutr. Food Res. 2010, 54, 760-766. [CrossRef] [PubMed]

36. Naveed, M.; Hejazi, V.; Abbas, M.; Kamboh, A.A.; Khan, G.J.; Shumzaid, M.; Ahmad, F.; Babazadeh, D.; FangFang, X.; ModarresiGhazani, F.; et al. Chlorogenic acid (CGA): A pharmacological review and call for further research. Biomed. Pharmacother. Biomed. Pharmacother. 2018, 97, 67-74. [CrossRef]

37. Lozano-Sánchez, J.; Borrás-Linares, I.; Sass-Kiss, A.; Segura-Carretero, A. Chapter 13-Chromatographic Technique: HighPerformance Liquid Chromatography (HPLC). In Modern Techniques for Food Authentication, 2nd ed.; Sun, D.-W., Ed.; Academic Press: Cambridge, MA, USA, 2018; pp. 459-526. ISBN 978-0-12-814264-6.

38. Liao, W.; Rui, Y. Evaluation of Chlorogenic Acid in Flos Lonicerae by HPLC Method. Asian J. Chem. 2010, 22, 1859-1863. Available online: http:/ / www.webofscience.com/wos/woscc/full-record/WOS:000274581700031 (accessed on 1 October 2021).

39. He, Y.; Su, J.; Yang, Q.; Liu, H.; Zhang, W. Simultaneous determination of chlorogenic acid and vitexin 2"-rhamnoside in Crataegi Fructus extracts by HPLC. J. Chin. Mater. Med. 2012, 37, 829-831.

40. Borisova-Jan, L.; Fransson, D.; Claeson, P.; Burman, R. Liquid Chromatographic Method for the Determination of Caffeoylquinic Acid Derivates in Hieracium pilosella L. Phytochem. Anal. 2017, 28, 550-557. [CrossRef] [PubMed]

41. Zhai, K.-F.; Duan, H.; Shi, S.-X.; Liu, L.-L.; Cao, W.-G.; Gao, G.-Z.; Shan, L.-L. Synchronised determination of chlorogenic acid and five flavonoids in mulberry leaves using HPLC with photodiode array detection. Qual. Assur. Saf. Crops Foods 2018, 10, 175-182. [CrossRef]

42. Velkoska-Markovska, L.; Jankulovska, M.S.; Petanovska-Ilievska, B.; Hristovski, K. Development and validation of RRLC-UV method for determination of chlorogenic acid in green coffee. Acta Chromatogr. 2020, 32, 34-38. [CrossRef]

43. Magalhaes, L.M.; Machado, S.; Segundo, M.A.; Lopes, J.A.; Pascoa, R.N.M.J. Rapid assessment of bioactive phenolics and methylxanthines in spent coffee grounds by FT-NIR spectroscopy. Talanta 2016, 147, 460-467. [CrossRef]

44. Xia, Z.; Sun, Y.; Cai, C.; He, Y.; Nie, P. Rapid Determination of Chlorogenic Acid, Luteoloside and 3,5-O-dicaffeoylquinic Acid in Chrysanthemum Using Near-Infrared Spectroscopy. Sensors 2019, 19, 1981. [CrossRef] [PubMed]

45. Yan, H.; Pu, Z.; Wang, Y.; Guo, S.; Wang, T.; Li, S.; Zhang, Z.; Zhou, G.; Zhan, Z.; Duan, J. Rapid qualitative identification and quantitative analysis of Flos Mume based on Fourier transform near infrared spectroscopy. Spectrochim. Acta Part A Mol. Biomol. Spectrosc. 2021, 249, 119344. [CrossRef]

46. Fast Determination of Chlorogenic Acid in Tobacco Residues Using Microwave-Assisted Extraction and Capillary Zone Electrophoresis Technique-Web of Science Core Collection. Available online: https:/ / www-webofscience-com.am.e-nformation.ro/ wos/woscc/full-record/WOS:000282480500015 (accessed on 2 October 2021).

47. Tang, Z.; Zang, S.; Zhang, X. Detection of Chlorogenic Acid in Honeysuckle Using Infrared-Assisted Extraction Followed by Capillary Electrophoresis with UV Detector. J. Chromatogr. Sci. 2012, 50, 76-80. [CrossRef] [PubMed]

48. Gatea, F.; Teodor, E.D.; Matei, A.O.; Badea, G.I.; Radu, G.L. Capillary Electrophoresis Method for 20 Polyphenols Separation in Propolis and Plant Extracts. Food Anal. Methods 2015, 8, 1197-1206. [CrossRef]

49. Wang, X.; Wang, J.; Yang, N. Chemiluminescent determination of chlorogenic acid in fruits. Food Chem. 2007, 102, 422-426. [CrossRef]

50. Chen, X.; Mao, J.; Wen, F.; Xu, X. Determination of Phenolic Acids in Botanical Pharmaceutical Products by Capillary Electrophoresis with Chemiluminescence Detection. Anal. Lett. 2021, 54, 817-829. [CrossRef]

51. Chao, M.; Ma, X. Voltammetric determination of chlorogenic acid in pharmaceutical products using poly(aminosulfonic acid) modified glassy carbon electrode. J. Food Drug Anal. 2014, 22, 512-519. [CrossRef]

52. Ma, X.; Yang, H.; Xiong, H.; Li, X.; Gao, J.; Gao, Y. Electrochemical Behavior and Determination of Chlorogenic Acid Based on Multi-Walled Carbon Nanotubes Modified Screen-Printed Electrode. Sensors 2016, 16, 1797. [CrossRef]

53. Apetrei, I.; Apetrei, C. Development of a Novel Biosensor Based on Tyrosinase/Platinum Nanoparticles/Chitosan/Graphene Nanostructured Layer with Applicability in Bioanalysis. Materials 2019, 12, 1009. [CrossRef]

54. Yola, M.L.; Atar, N.; Üstündağ, Z.; Solak, A.O. A novel voltammetric sensor based on p-aminothiophenol functionalized graphene oxide/gold nanoparticles for determining quercetin in the presence of ascorbic acid. J. Electroanal. Chem. 2013, 698, 9-16. [CrossRef]

55. Bard, A.J.; Faulkner, L.R. Electrochemical Methods: Fundamentals and Applications, 2nd ed.; Wiley: New York, NY, USA, 2001; ISBN 978-0-471-04372-0. 
56. Bounegru, A.V.; Apetrei, C. Laccase and Tyrosinase Biosensors Used in the Determination of Hydroxycinnamic Acids. Int. J. Mol. Sci. 2021, 22, 4811. [CrossRef]

57. Bounegru, A.V.; Apetrei, C. Carbonaceous Nanomaterials Employed in the Development of Electrochemical Sensors Based on Screen-Printing Technique-A Review. Catalysts 2020, 10, 680. [CrossRef]

58. Munteanu, I.-G.; Apetrei, C. Electrochemical Determination of Chlorogenic Acid in Nutraceuticals Using Voltammetric Sensors Based on Screen-Printed Carbon Electrode Modified with Graphene and Gold Nanoparticles. Int. J. Mol. Sci. 2021, $22,8897$. [CrossRef]

59. Rodrigues Santos, W.D.J.; Santhiago, M.; Pagotto Yoshida, I.V.; Kubota, L.T. Novel electrochemical sensor for the selective recognition of chlorogenic acid. Anal. Chim. Acta 2011, 695, 44-50. [CrossRef]

60. Chen, Y.; Huang, W.; Chen, K.; Zhang, T.; Wang, Y.; Wang, J. A novel electrochemical sensor based on core-shell-structured metal-organic frameworks: The outstanding analytical performance towards chlorogenic acid. Talanta 2019, 196, 85-91. [CrossRef] [PubMed]

61. Wang, Y.; Chen, H.; Hu, X.; Yu, H. Highly stable and ultrasensitive chlorogenic acid sensor based on metal-organic frameworks/titanium dioxide nanocomposites. Analyst 2016, 141, 4647-4653. [CrossRef] [PubMed]

62. Mohammadi, N.; Najafi, M.; Adeh, N.B. Highly defective mesoporous carbon-ionic liquid paste electrode as sensitive voltammetric sensor for determination of chlorogenic acid in herbal extracts. Sens. Actuators B Chem. 2017, 243, 838-846. [CrossRef]

63. Zhang, T.; Chen, Y.; Huang, W.; Wang, Y.; Hu, X. A novel AuNPs-doped COFs composite as electrochemical probe for chlorogenic acid detection with enhanced sensitivity and stability. Sens. Actuators B Chem. 2018, 276, 362-369. [CrossRef]

64. Chokkareddy, R.; Redhi, G.G.; Karthick, T. A lignin polymer nanocomposite based electrochemical sensor for the sensitive detection of chlorogenic acid in coffee samples. Heliyon 2019, 5, e01457. [CrossRef] [PubMed]

65. Zhang, T.; Liu, M.; Zhang, Q.; Wang, Y.; Kong, X.; Wang, L.; Wang, H.; Zhang, Y. Sensitive determination of chlorogenic acid in pharmaceutical products based on the decoration of 3D macroporous carbon with Au nanoparticles via polyoxometalates. Analyst 2017, 142, 2603-2609. [CrossRef]

66. Cheng, W.; Huang, J.; Liu, C.; Zeng, Q.; Tong, Y.; Wang, L.; Cheng, F. High sensitivity chlorogenic acid detection based on multiple layer-by-layer self-assembly films of chitosan and multi-walled carbon nanotubes on a glassy carbon electrode. RSC Adv. 2017, 7, 6950-6956. [CrossRef]

67. Teker, T.; Aslanoglu, M. A novel voltammetric sensing platform based on carbon nanotubes-niobium nanoparticles for the determination of chlorogenic acid. Arab. J. Chem. 2020, 13, 5517-5525. [CrossRef]

68. Huang, Z.; Zhang, Y.; Sun, J.; Chen, S.; Chen, Y.; Fang, Y. Nanomolar detection of chlorogenic acid at the cross-section surface of the pencil lead electrode. Sens. Actuators B Chem. 2020, 321, 128550. [CrossRef]

69. Wee, Y.; Park, S.; Kwon, Y.H.; Ju, Y.; Yeon, K.-M.; Kim, J. Tyrosinase-immobilized CNT based biosensor for highly-sensitive detection of phenolic compounds. Biosens. Bioelectron. 2019, 132, 279-285. [CrossRef] [PubMed]

70. Mazlan, S.Z.; Lee, Y.H.; Hanifah, S.A. A New Laccase Based Biosensor for Tartrazine. Sensors 2017, 17, 2859. [CrossRef] [PubMed]

71. Stasyuk, N.; Gayda, G.; Zakalskiy, A.; Zakalska, O.; Serkiz, R.; Gonchar, M. Amperometric biosensors based on oxidases and PtRu nanoparticles as artificial peroxidase. Food Chem. 2019, 285, 213-220. [CrossRef]

72. de Macêdo, I.Y.L.; Garcia, L.F.; Oliveira Neto, J.R.; de Siqueira Leite, K.C.; Ferreira, V.S.; Ghedini, P.C.; de Souza Gil, E. Electroanalytical tools for antioxidant evaluation of red fruits dry extracts. Food Chem. 2017, 217, 326-331. [CrossRef]

73. Dinu, A.; Apetrei, C. A Review on Electrochemical Sensors and Biosensors Used in Phenylalanine Electroanalysis. Sensors 2020, 20, 2496. [CrossRef]

74. Ye, Y.; Ji, J.; Sun, Z.; Shen, P.; Sun, X. Recent advances in electrochemical biosensors for antioxidant analysis in foodstuff. TrAC Trends Anal. Chem. 2019, 122, 115718. [CrossRef]

75. Moccelini, S.K.; Spinelli, A.; Vieira, I.C. Biosensors based on bean sprout homogenate immobilized in chitosan microspheres and silica for determination of chlorogenic acid. Enzym. Microb. Technol. 2008, 43, 381-387. [CrossRef]

76. Fernandes, S.C.; Moccelini, S.K.; Scheeren, C.W.; Migowski, P.; Dupont, J.; Heller, M.; Micke, G.A.; Vieira, I.C. Biosensor for chlorogenic acid based on an ionic liquid containing iridium nanoparticles and polyphenol oxidase. Talanta 2009, 79, 222-228. [CrossRef] [PubMed]

77. Vasilescu, I.; Eremia, S.A.V.; Penu, R.; Albu, C.; Radoi, A.; Litescu, S.C.; Radu, G.-L. Disposable dual sensor array for simultaneous determination of chlorogenic acid and caffeine from coffee. RSC Adv. 2014, 5, 261-268. [CrossRef]

78. Vlamidis, Y.; Gualandi, I.; Tonelli, D. Amperometric biosensors based on reduced GO and MWCNTs composite for polyphenols detection in fruit juices. J. Electroanal. Chem. 2017, 799, 285-292. [CrossRef]

79. Tulli, F.; Gulotta, F.A.; Martino, D.M.; Paz Zanini, V.I.; Borsarelli, C.D. Ultrasensitive Amperometric Biosensing of Polyphenols Using Horseradish Peroxidase Immobilized in a Laponite/Au/DNA-Bioinspired Polycation Nanocomposite. J. Electrochem. Soc. 2018, 165, B452-B457. [CrossRef]

80. Akyuz, E.; Baskan, K.S.; Tutem, E.; Apak, R. Novel Protein-Based Solid-Biosensor for Determining Pro-oxidant Activity of Phenolic Compounds. J. Agric. Food Chem. 2017, 65, 5821-5830. [CrossRef]

81. Gurung, N.; Ray, S.; Bose, S.; Rai, V. A broader view: Microbial enzymes and their relevance in industries, medicine, and beyond. BioMed Res. Int. 2013, 2013, 329121. [CrossRef] 